\title{
Guía de atención integral con evaluación económica para la prevención, el diagnóstico, el tratamiento y el seguimiento del cáncer de piel no melanoma: queratosis actínica
}

Comprehensive Guide, with economic assessment, for the prevention, diagnosis, treatment and monitoring of non melanoma skin cancer: actinic keratosis

\section{Álvaro Acosta ${ }^{1}$, Xavier Rueda ${ }^{2}$, Guillermo Sánchez ${ }^{3}$, Ingrid Arévalo ${ }^{4}$, Hugo Eduardo Herrera $^{5}$, Ana Francisca Ramírez ${ }^{6}$, Guillermo Jiménez ${ }^{7}$, Omar Darío Segura $^{8}$, Magda Cepeda $^{9}$, Andrea Esperanza Rodríguez ${ }^{10}$, John Alexander Nova ${ }^{11}$, Martha Cecilia Valbuena ${ }^{12}$}

1. Dermatólogo oncólogo; coordinador, Dermatología Oncológica, Instituto Nacional de Cancerología; profesor titular, Universidad Nacional de Colombia, Bogotá, D.C., Colombia.

2. Dermatólogo oncólogo, Instituto Nacional de Cancerología Bogotá, D.C., Colombia.

3. Especialista en Epidemiología General, magíster en Epidemiología Clínica, doctor en Salud Pública, Fundación Universitaria de Ciencias de la Salud, Bogotá, D.C., Colombia.

4. Magíster en Epidemiología Clínica y PhD (c) en Medicina Preventiva y Salud Pública, Fundación Universitaria de Ciencias de la Salud, Bogotá, D.C., Colombia.

5. Especialista en Dermatología, Asociación Colombiana de Dermatología y Cirugía Dermatológica y Universidad El Bosque Bogotá, D.C., Colombia.

6. Especialista en Dermatología y Dermatología Oncológica, Asociación Colombiana de Dermatología y Cirugía Dermatológica, Bogotá, D.C., Colombia.

7. Especialista en Dermatología, Dermatología Oncológica y Cirugía Dermatológica, Asociación Colombiana de Dermatología y Cirugía Dermatológica, Bogotá, D.C., Colombia

8. Magíster en Epidemiología Clínica, Epidemiólogo de Campo, $\mathrm{PhD}$ (c) en Salud Pública, Fundación Universitaria de Ciencias de la Salud, Bogotá, D.C., Colombia.

9. Magíster en Epidemiología Clínica, Fundación Universitaria de Ciencias de la Salud, Bogotá, D.C., Colombia.

10. Especialista en Estadística Aplicada, magíster en Epidemiología Clínica, Fundación Universitaria de Ciencias de la Salud, Bogotá, D.C., Colombia.

11. Especialista en Dermatología, magíster en Epidemiología Clínica, Centro Dermatológico Federico Lleras Acosta Bogotá, D.C., Colombia.

12. Especialista en Dermatología y Fotodermatología, Centro Dermatológico Federico Lleras Acosta, Bogotá, D.C., Colombia.

\section{RESUMEN}

OBJETIVO: Generar recomendaciones para la prevención, el diagnóstico, el tratamiento y el seguimiento del cáncer de piel no melanoma: queratosis actínica, con el fin de apoyar al personal de salud en los diferentes servicios, buscando garantizar una atención integral, homogénea, con calidad, equidad y eficiencia para los pacientes con esta enfermedad; además, generar indicadores de seguimiento a las recomendaciones de la guía, acordes al contexto nacional.

MATERIALES Y MÉTODOS: Se conformó el grupo desarrollador del la guía con un grupo interdisciplinario de profesionales y representantes de pacientes. Se establecieron el alcance, los objetivos, las preguntas y los resultados de la guía. Se hizo una búsqueda de guías sobre manejo de la queratosis actínica, pero ninguna de las guías encontradas se podía adaptar, por lo que se decidió elaborar una nueva guía. Se hizo
Correspondencia:

Álvaro Acosta

Email:

aeacostam@unal.edu.co

Recibido: 1 de abril de 2015 Aceptado: 5 de mayo de 2015 
una búsqueda bibliográfica sobre revisiones sistemáticas, metaanálisis, ensayos clínicos, estudios de cohortes, estudios de casos y controles, en las bases de datos Medline (vía Pubmed y Ovid), Embase y Central (vía Ovid). Se evaluó la calidad metodológica de los artículos seleccionados. Posteriormente, se elaboraron las tablas de evidencia por medio del software GRADEpro ${ }^{\circledR} 3.6$ y se generaron las recomendaciones bajo la metodología GRADE mediante consensos de expertos.

RESULTADOS: Se presentan las recomendaciones de prevención primaria, prevención secundaria, tratamiento (quirúrgico y no quirúrgico) y seguimiento de la queratosis actínica. Además, se formulan varias preguntas generales que sirven al lector para contextualizarse en el tema de la guía de práctica clínica, pero que no generan recomendaciones.

CONCLUSIONES: Se considera que las recomendaciones relacionadas con la prevención son prioritarias en el proceso de implementación de la guía. Se presentan cuatro indicadores de auditoría para la guía de práctica clínica, relacionados con prevención, diagnóstico y tratamiento.

PALABRAS CLAVE: guía de práctica clínica, neoplasias cutáneas, queratosis actínica.

\section{SUMMARY}

OBJECTIVE: To generate recommendations for the prevention, diagnosis, treatment and follow-up for the non-melanoma skin cancer actinic keratosis, providing support for the health professionals in the different services in charge of its attention, looking to guarantee integral, homogeneous attention, with quality, equity and efficiency for the patients with this pathology, as well as generating follow-up indicators to the guide's recommendation in accordance with the national context.

MATERIALS AND METHODS: The Guide Development Group was formed by an interdisciplinary group of professionals and patient representatives. Reach, objectives, questions, and outcomes for the guide were defined. A guide search about actinic keratosis handling was performed, but none of them was found to be adaptable, therefore writing a guide de novo was decided. A literature search was performed, including systematic reviews, metaanalyses, clinical trials, cohort studies, and case-control studies in Medline (via Pubmed and Ovid), Embasse and Central (via Ovid) databases. The methodological quality of the selected articles was evaluated. Subsequently, evidence tables were made through the GRADEpro® 3.6 software and recommendations were generated under the GRADE technology through experts' consensus.

RESULTS: Actinic keratosis primary prevention, secondary prevention, treatment (surgical and non-surgical) and follow-up recommendations are presented. Additionally, several general questions are presented which serve the reader to contextualize the subject of clinical practice guidelines, but which do not generate recommendations.

CONCLUSIONS: It is considered that the recommendations relating to prevention are a priority in the guide's implementation process. Four auditing indicators for the clinical practice guidelines are presented relating to prevention, diagnosis, and treatment.

KEYWORDS: Clinical practice guide, skin neoplasia, actinic keratosis.

\section{Conflictos de interés:}

A partir del momento en el que se estructuró la propuesta y se conformó el Grupo Desarrollador de la Guía, se declararon y evaluaron los posibles conflictos de intereses. Una vez la propuesta fue aprobada para su ejecución, nuevamente, y basados en lo planteado por la "Guía metodológica para la elaboración de guías de práctica clínica con evaluación económica en el Sistema General de Seguridad Social en Salud colombiano" del Ministerio de Salud y Protección Social, el grupo de expertos clínicos, expertos en metodología y el equipo de evaluación económica revisaron y declararon sus posibles conflictos de intereses. Un comité ad hoc revisó cada caso y se pronunció frente al particular. Los detalles se presentan en la versión completa de la presente guía.

Agradecimiento especial a los Doctores:

\section{Mariam Carolina Rolón}

Especialista en Dermatopatología y Patología Oncológica, Instituto Nacional de Cancerología, Bogotá, D.C., Colombia.

\section{Enrique Cadena}

Especialista en Cirugía de Cabeza y Cuello, Instituto Nacional de Cancerología, Bogotá, D.C., Colombia.

\section{Victoria Eugenia Franco}

Especialista en Dermatología, Centro Dermatológico Federico Lleras Acosta, Bogotá, D.C., Colombia. 


\section{PROPÓSITO Y ALCANCE}

Esta guía de práctica clínica, como su nombre lo dice, tiene como objetivo hacer recomendaciones basadas en la 'evidencia' para la prevención, la detección, el tratamiento y el seguimiento de las queratosis actínicas, con el fin de apoyar al personal de salud de los diferentes niveles de atención, buscando garantizar una atención integral, homogénea, con calidad, equidad y eficiencia, para los pacientes con esta condición.

Está dirigida al personal clínico-asistencial que brinda cuidados a pacientes en la prevención, el diagnóstico, el tratamiento y el seguimiento de la queratosis actínica, en los diferentes grados de complejidad de los servicios involucrados en el manejo de esta enfermedad en el marco del Sistema General de Seguridad Social en Salud (SGSSS) (médicos generales, médicos familiares, médicos especialistas en Dermatología, Patología, Cirugía Plástica, profesionales de Enfermería, geriatras y otros profesionales de la salud que manejen esta enfermedad). El tratamiento de condiciones específicas por parte de subespecialistas, amerita recomendaciones específicas que exceden el alcance de la presente propuesta.

También se dirige a quienes toman decisiones administrativas, tanto en el ámbito hospitalario como en el de las aseguradoras, pagadores del gasto en la salud y en la generación de políticas de salud.

Esta guía de práctica clínica hace recomendaciones específicas para las preguntas formuladas y define las competencias profesionales del equipo involucrado en el manejo de esta enfermedad. Se hacen recomendaciones que pueden ser utilizadas en los diferentes grados de complejidad de los servicios encargados de la atención dentro del SGSSS.

El presente documento presenta un resumen de la información contenida en la versión completa de la guía de práctica clínica, la cual puede ser consultada en la página del Ministerio de Salud y Protección Social (http:// gpc.minsalud.gov.co/Pages/Default.aspx).

\section{INTRODUCCIÓN Y JUSTIFICACIÓN DE LA GUIIA}

La queratosis actínica es una neoplasia intraepidérmica temprana que puede progresar a un carcinoma escamocelular cutáneo invasor. Es producida por la exposición crónica a la radiación ultravioleta y se localiza con predilección en las áreas expuestas al sol. En diferentes estudios europeos se han estimado prevalencias alrededor del $20 \%$ en adultos mayores de 60 años, con incidencias anuales de 149 casos por 1.000 personas ${ }^{1,2}$. El principal factor de riesgo ambiental es la exposición solar desde la infancia, como lo demuestran varios estudios de migraciones en Australia. Se han implicado tanto la exposición solar crónica como la exposición solar intermitente con quemaduras solares. La radiación ultravioleta del sol es un carcinógeno completo. Los rayos ultravioletas B (UVB) (290-320 nm) son los más dañinos por su interacción directa con los ácidos nucleicos de los queratinocitos de la piel. Los rayos ultravioletas A (UVA) (320-340 nm) también contribuyen al daño celular por intermedio de la creación de especies reactivas del oxígeno. Además, los rayos ultravioleta generan un estado de inmunosupresión local que favorece el desarrollo de los tumores. Entre los cambios moleculares más tempranos, se encuentra la mutación del gen $p 53$ que codifica la proteína del mismo nombre. La proteína p53 promueve la reparación del ADN y, en caso de que esta sea infructuosa, lleva la célula afectada a un proceso de apoptosis. Al mutarse este gen, las células afectadas adquieren resistencia a la apoptosis y una ventaja en la proliferación con respecto a las células normales. Si se suman otras mutaciones en otros genes, como $H-R A S$ y p16, las células progresan y se multiplican y, finalmente, se desarrolla un carcinoma escamocelular.

Los procesos inflamatorios juegan también un papel importante en el desarrollo de los tumores. En situaciones patológicas, se ha encontrado una sobrexpresión de la ciclooxigenasa de tipo 2 (COX-2), que facilitaría el desarrollo de tumores cutáneos. Los experimentos con ratones transgénicos que sobreexpresan esta enzima, han demostrado que son más propensos a desarrollar tumores de piel radioinducidos. Por el contrario, los ratones transgénicos deficientes en COX-2 presentan una reducción del $75 \%$ de los tumores radioinducidos, con respecto a la población normal de ratones. El aumento de COX-2 se asocia con mayor proliferación celular, aumento en la expresión de proteínas antiapoptóticas de la familia de BCL-2 y con la angiogénesis.

El riesgo de progresión de una queratosis actínica a un carcinoma escamocelular en un año, es bajo (o,13 \% y $0,24 \%$, según los dos estudios de seguimiento mejor documentados). Con estos dos datos, Dodson, en 1991, calculó el riesgo de desarrollar un carcinoma escamocelular a 10 años, teniendo en cuenta que la mayoría de los pacientes presenta más de una queratosis actínica (en promedio, 7,7 por persona) $)^{3}$. Si se considera la cifra de $0,13 \%$, el riesgo de presentar un carcinoma escamocelular en 10 años es del $10 \%$. Si se opta por la cifra de $0,24 \%$, el riesgo sube a $18 \%$. Otro dato importante que arrojó el estudio australiano de Marks es que, en un año, el $36,4 \%$ de las queratosis actínicas presentes al inicio 
desaparecen, pero también se observa la aparición de nuevas lesiones en 21,8 \% de los casos ${ }^{4}$.

En este contexto, el Ministerio de Salud y Protección Social encargó a la Fundación Universitaria de Ciencias de la Salud, en conjunto con el Instituto Nacional de Cancerología y el Centro Dermatológico Federico Lleras, el desarrollo de una guía de práctica clínica sobre el manejo de la queratosis actínica. Esta guía de práctica clínica basada en la 'evidencia' puede ofrecer a los ciudadanos las mejores alternativas de prevención, diagnóstico, tratamiento y seguimiento, para una enfermedad que, como se ha mencionado, si se diagnostica a tiempo, tiene un pronóstico excelente, con un bajo costo para el sistema y sin mayores repercusiones en términos de calidad de vida. Las guías clínicas del Ministerio, una vez publicadas, serán la referencia para la aplicación de procesos asistenciales en las instituciones del SGSSS.

La presente guía busca ser una herramienta de ayuda para el personal de salud, los pacientes y las demás partes involucradas en la prestación de los servicios de salud. En ella se incluyen temas que abarcan desde las manifestaciones clínicas de la enfermedad hasta los tratamientos y seguimientos recomendados según la información disponible al momento de su elaboración, haciéndose énfasis especial en la prevención de la enfermedad.

\section{MATERIALES Y MÉTODOS}

El grupo desarrollador de la guía para la prevención, diagnóstico, tratamiento y seguimiento del cáncer de piel no melanoma: queratosis actínica, siguió los lineamientos presentados en la "Guía metodológica para la elaboración de guías de práctica clínica con evaluación económica en el Sistema de General de Seguridad Social en Salud" realizada por el Ministerio de Salud y Protección Social de Colombia junto con Colciencias, el Centro de Estudios e Investigación en Salud de la Fundación Santafé de Bogotá y la Escuela de Salud Pública de la Universidad de Harvard ${ }^{5,6}$. El grupo desarrollador de la guía estuvo conformado por expertos temáticos adscritos a sociedades científicas, incluyendo dermatólogos, dermatooncólogos, dermatopatólogos, enfermeras, epidemiólogos clínicos, salubristas y representantes de pacientes, así como expertos en Economía de la Salud para desarrollar las evaluaciones económicas de la guías de práctica clínica. Todos los profesionales incluidos presentaron su declaración sobre conflicto de intereses. Los representantes de los pacientes participaron en las diferentes fases del proceso de la elaboración de las guías de práctica clínica.

Una vez formuladas las preguntas clínicas, el grupo desarrollador de la guía procedió a hacer una búsqueda sistemática de guías de práctica clínica, orientada a identificar las guías nacionales e internacionales disponibles entre el 2000 y el 2013, de acuerdo con lo sugerido por el "Manual metodológico del Sistema Nacional de Salud de España"7. Los sitios consultados fueron: AHRQ National Guidelines Clearinghouse, NHS National Library of Guidelines, GuiaSalud, Scottish Intercollegiate Guidelines Network, National Institute for Clinical Excellence, Australian National Health and Medical Research Council, New Zealand Guidelines Group, Geneva Foundation for Medical Education and Research, Organización Mundial de la Salud (OMS), Organización Panamericana de la Salud (OPS), ICSI Health Care Guidelines, Singapore Ministry of Health Guidelines Projec, TRIP database, Excelencia Clínica, Medline a través de PubMed, Embase a través de Ovid y Lilacs a través de la Biblioteca Virtual en Salud. En el caso de la presente guía de práctica clínica, si bien el grupo desarrollador identificó referencias en la búsqueda bibliográfica de guías, estas no proporcionaban 'evidencia' bajo un proceso sistemático de búsquedas de la literatura, ni presentaban información de la valoración de la 'evidencia' por medio de un método sistemático que permitiese la generación transparente de recomendaciones. En este caso, el grupo desarrollador de la guía decidió no adaptar la información de las referencias identificadas, sino pasar a un desarrollo de novo de esta guía de práctica clínica.

Posteriormente, se procedió a la revisión bibliográfica de los aspectos clínicos incluidos dentro de la guía, acorde con los lineamientos sugeridos por la guía metodológica del Ministerio de Salud y Protección Social ${ }^{5,6}$. Se hizo una búsqueda de la literatura de revisiones sistemáticas y metaanálisis para las preguntas de la guía; las bases de datos seleccionadas para la búsqueda de evidencia fueron Medline (vía Pubmed y Ovid), Embase y Central (vía Ovid). La calidad de dichas revisiones fue evaluada por medio del instrumento AMSTAR. Para algunas revisiones sistemáticas evaluadas, fue necesario actualizar la información con la búsqueda de estudios primarios recientes. Cuando no se encontraron revisiones sistemáticas, se procedió a la búsqueda de artículos primarios, comenzando por ensayos clínicos, y siguiendo por estudios de cohortes, de casos y controles, y estudios descriptivos.

Para la selección de los artículos, dos miembros del grupo desarrollador de la guía seleccionaron los títulos y resúmenes resultantes de la búsqueda sistemática de la literatura. Después de esta selección, se obtuvieron y revisaron los textos completos de los artículos seleccionados. Cualquier discrepancia entre los evaluadores fue resuelta por consenso. Los resultados de la búsqueda definitiva 
fueron almacenados en el programa de manejo de referencias Endnote $\mathrm{X}_{5}{ }^{\mathrm{TM}}$. Asimismo, para la evaluación del riesgo de sesgo asociado a dichos estudios, se emplearon las escalas de evaluación sugeridas por el Scottish International Guidelines Network (SIGN) para los temas de estudios de intervenciones y observacionales, así como el QUADAS-II para los temas de estudios diagnósticos. Los resultados de esta revisión se consignaron en tablas de 'evidencia' elaboradas por medio del software GRADEprofiler, versión 3.6, que resumieron los datos de la información valorada. Dichas tablas incluyeron información referente a datos de identificación del estudio evaluado, diseño, población participante, resultados (incluyendo medidas de efecto, diagnósticas o frecuencias, según el caso), conclusiones, nivel de 'evidencia' y comentarios, si hubiese lugar.

Para la formulación de recomendaciones, se tomaron como insumo las tablas de 'evidencia' junto con el material bibliográfico consultado y la experiencia clínica de los miembros del grupo desarrollador de la guía. Para cada pregunta con 'evidencia' disponible, se realizó un consenso informal en el que participaron expertos clínicos y metodológicos, y los representantes de los pacientes en el grupo desarrollador de la guía. Para la generación de recomendaciones, se utilizó la metodología del GRADE Working Group, la cual incluyó información referente a volumen y calidad de la 'evidencia' identificada, balance daño-beneficio de la intervención evaluada, necesidad de recursos, y costos y preferencias de los pacientes. Además de incluir recomendaciones clínicas basadas en la 'evidencia', el grupo desarrollador de la guía incluyó puntos de buenas prácticas clínicas para reforzar conductas positivas en el manejo de los pacientes objeto de la guía, de las cuales no se cuestionan sus efectos benéficos y no conllevan riesgos asociados a su administración. En los casos en que no se encontró 'evidencia' para sustentar las recomendaciones o en temas críticos para la práctica clínica, se optó por el uso de métodos formales de consenso de expertos para la generación de recomendaciones. En este caso, se usó el método Delphi modificado (método de apropiación RAND/UCLA). Los niveles de 'evidencia' y la fuerza de las recomendaciones fueron graduadas por medio de la metodología GRADE (TABLA 1).

\section{Niveles DE 'EVIDENCIA' - CALIDAD DE LA 'EVIDENCIA' GRADE}

\begin{tabular}{ll}
\hline \multicolumn{1}{c}{ JUICIO } & CARACTERÍSTICAS \\
\hline Alta & Es muy poco probable que nuevos estudios cambien la confianza que se tiene en el resultado estimado. \\
Moderada & $\begin{array}{l}\text { Es probable que nuevos estudios tengan un impacto importante en la confianza que se tiene en el } \\
\text { resultado estimado y que estos puedan modificar el resultado. }\end{array}$ \\
Baja & $\begin{array}{l}\text { Es muy probable que nuevos estudios tengan un impacto importante en la confianza que se tiene en el } \\
\text { resultado estimado y que estos puedan modificar el resultado. }\end{array}$ \\
Muy baja & Cualquier resultado estimado es muy incierto. \\
\hline
\end{tabular}

\section{FUERZA DE LA RECOMENDACIÓN GRADE}

\begin{tabular}{|c|c|c|}
\hline \multicolumn{2}{|c|}{ FUERZA DE LA RECOMENDACIÓN } & SIGNIFICADO \\
\hline & Fuerte, a favor & $\begin{array}{l}\text { Las consecuencias deseables claramente sobrepasan las consecuencias indeseables. } \\
\text { SE RECOMIENDA EMPLEAR LA INTERVENCION EVALUADA. }\end{array}$ \\
\hline & Débil, a favor & $\begin{array}{l}\text { Las consecuencias deseables probablemente sobrepasan las consecuencias indeseables. } \\
\text { SE SUGIERE EMPLEAR LA INTERVENCION EVALUADA. }\end{array}$ \\
\hline & Débil, en contra & $\begin{array}{l}\text { Las consecuencias indeseables probablemente sobrepasan las consecuencias deseables. } \\
\text { SE SUGIERE NO EMPLEAR LA INTERVENCION EVALUADA. }\end{array}$ \\
\hline & Fuerte, en contra & $\begin{array}{l}\text { Las consecuencias indeseables claramente sobrepasan las consecuencias deseables. } \\
\text { SE RECOMIENDA NO EMPLEAR LA INTERVENCIÓN EVALUADA. }\end{array}$ \\
\hline & $\begin{array}{l}\text { Punto de buena } \\
\text { práctica }\end{array}$ & $\begin{array}{l}\text { Recomendación considerada como incuestionable o irrebatible ya que sus beneficios en } \\
\text { la práctica clínica son claros. }\end{array}$ \\
\hline
\end{tabular}

TABLA 1._Niveles de 'evidencia’ y fuerza de la recomendación según la metodología GRADE. 


\section{"EL PRINCIPAL FACTOR DE RIESGO ES LA EXPOSICIÓN TEMPRANA (QUEMADURAS SOLARES ANTES DE LOS 20 AÑOS) Y CRÓNICA A LOS RAYOS ULTRAVIOLETA DEL SOL"}

El grupo desarrollador de la guía incorporó la perspectiva de los pacientes mediante diferentes estrategias, a lo largo del proceso de desarrollo de la guía de práctica clínica. Se incluyeron hombres y mujeres mayores de edad, con diagnóstico confirmado de cáncer de piel no melanoma: queratosis actínica, cáncer escamocelular o cáncer basocelular. Las etapas o momentos para la inclusión de la perspectiva de los pacientes con cáncer de piel no melanoma, fueron: identificación de los temas de mayor relevancia que debían incluirse según la experiencia de los sujetos que han padecido cáncer de piel no melanoma, divulgación y discusión con los pacientes sobre las recomendaciones emanadas por la guía de práctica clínica y validación de los contenidos de la guía para pacientes. Por último, se vincularon los diferentes grupos de interés en diferentes fases de la guía mediante mecanismos directos o indirectos (representaciones de agremiaciones, laboratoratorios, sociedades científicas, entre otros).

\section{1. ¿Cómo se define la queratosis actínica?}

La queratosis actínica, o queratosis solar, es una neoplasia intraepidérmica temprana según los estudios realizados en la última década, por lo tanto, se debe clasificar de manera análoga a la displasia cervical: KIN (Keratinocytic Intraepithelial Neoplasia) ${ }^{8}$. Las mutaciones genéticas en las queratosis actínicas son similares a las que se encuentran en los carcinomas escamocelulares, lo que sugiere la progresión de las primeras a las segundas ${ }^{9}$. Asimismo, desde el punto de vista histológico, se observa una progresión de una displasia focal en la queratosis actínica a una displasia completa de la epidermis en los carcinomas escamocelulares in situ que puede llevar a un carcinoma escamocelular invasor ${ }^{10}$.

\section{2. ¿Cuáles son los factores de riesgo identificados para la aparición de queratosis actínica?}

El principal factor de riesgo es la exposición temprana (quemaduras solares antes de los 20 años) y crónica a los rayos ultravioleta del sol ${ }^{11}$. Los rayos ultravioleta B (290$320 \mathrm{~nm}$ ) son las radiaciones electromagnéticas que más afectan los queratinocitos ya que producen mutaciones directas en el ADN. Los rayos ultravioleta A (320-400 $\mathrm{nm}$ ) actúan como cofactores de los rayos ultravioleta B al generar radicales libres y contribuir con la inmunosupresión a nivel local ${ }^{12,13}$. La intensidad de la radiación ultravioleta está directamente asociada con la latitud y la altitud. Las personas que han nacido en un lugar con altos índices de radiación ultravioleta, tienen un mayor riesgo de presentar queratosis actínica en su vida ${ }^{14}$. En un estudio japonés, los individuos que viven al sur del país, donde reciben dos veces más radiación ultravioleta que los que viven en el norte, presentaron tres veces más queratosis actínicas ${ }^{15}$. En relación con la altitud, se ha calculado que hay un aumento del 8 al $10 \%$ en la incidencia de queratosis actínica por cada $300 \mathrm{~m}$ de altitud ${ }^{16}$. Finalmente, los individuos que usan irregularmente protectores solares son más propensos a presentar queratosis actínica ${ }^{17}$.

Entre los factores de riesgo constitucionales, se encuentran: sexo masculino, edad avanzada, piel blanca $(14,1 \text { veces más riesgo que con piel oscura })^{18}$, fototipos I-III, antecedentes personales de cáncer de piel, trabajo al aire libre y nivel socioeconómico bajo. En Alemania, se encontró una asociación positiva con el sexo masculino $(\mathrm{OR}=3,9)$, la edad superior a 66 años $(\mathrm{OR}=1,1)$, la piel clara $(\mathrm{OR}=2,2)$, la historia personal de cáncer de piel $(\mathrm{OR}=4,8)$ y el trabajo al aire libre $(\mathrm{OR}=1,7)^{17}$. Los pacientes inmunosuprimidos, especialmente aquellos con trasplantes, tienen un riesgo aumentado de presentar queratosis 
actínica y otros cánceres de piel ${ }^{19}$. También, lo tienen los pacientes con vitiligo y ciertas genodermatosis, como albinismo, xeroderma pigmentoso, epidermodisplasia verruciforme, síndrome de Rothmund-Thomson y síndrome de Bloom ${ }^{20}$.

Otros factores de riesgo que pueden estar relacionados, son: el uso excesivo de cámaras bronceadoras; los tubos de fluorescencia utilizados en estas emiten $95 \%$ de rayos ultravioleta A y una pequeña porción de rayos ultravioleta B; el efecto a largo plazo en humanos es incierto, pero en ratones se ha demostrado que tanto los rayos ultravioleta A como los rayos ultravioleta B causan mutaciones en el $\mathrm{ADN}^{21}$. Otros posibles factores de riesgo descritos son la infección por el virus del papiloma humano ${ }^{22}$ y la exposición al arsénico ${ }^{23}$.

\section{ESTRATEGIAS DE PREVENCIÓN DE LA QUERATOSIS ACTÍNICA}

\section{3. ¿Cuáles son las estrategias más efectivas para la prevención primaria y la secundaria de la queratosis actínica?}

(Para una síntesis de las recomendaciones sobre estrategias de prevención, ver la TABLA 2).

\section{A. Medidas de prevención del cáncer de piel no melanoma en la población generat}

Un ensayo clínico de asignación aleatoria llevado a cabo en estudiantes universitarias con una intervención basada en la apariencia, mostró una reducción en el riesgo de la exposición prolongada al sol por medio del bronceo, a seis meses de intervención ${ }^{24}$ (CALIDAD MUY BAJA). En un segundo ensayo clínico en voluntarios de una comunidad, el empleo de mensajes de texto para recordarles el uso del protector solar, comparada con una población a la que no se le envió el mensaje de texto, incrementó en $20 \%$ la observancia de esta intervención a las seis semanas de seguimiento ( $\mathrm{p}<0,001)$. El $69 \%$ de los sujetos intervenidos manifestaron que seguirían recibiendo los mensajes y el $89 \%$ lo recomendaría a amigos y familiares ${ }^{25}$ (CALIDAD MODERADA).

En instituciones de preescolares se implementó la estrategia 'Block the sun, not the fun', dirigida principalmente a cuidadores de los centros educativos y, secundariamente, a los padres y los niños. Esta incluyó sesiones de trabajo con los grupos e información y paquetes de actividades para los padres. Aunque no se observaron cambios significativos en las actitudes y prácticas de protección solar de los niños por parte de los padres, se observó un cambio importante en el conocimiento y actitudes de los directores de los centros y los padres manifestaron satisfacción hacia las actividades realizadas en el colegio con el fin de reducir la exposición $^{26}$ (CALIDAD MODERADA). En otro estudio en entorno escolar, se compararon clases de colegios asignados aleatoriamente para ser intervenidos con el programa 'Living with the sun', el cual es un programa diseñado para que los niños mejoren sus conocimientos sobre la exposición al sol, y modificar positivamente sus comportamientos y actitudes hacia la protección solar. Al cabo de un año, aunque ambos grupos mostraron mejorar sus conocimientos sobre la protección solar, el grupo intervenido reportó mayor uso de protector solar, sombrero y sombrilla en la playa ${ }^{27}$ (CALIDAD MODERADA).

En 2002, se implementó una estrategia para incrementar la adopción de la política emitida por los Centers for Disease Control and Prevention (CDC) para reducir la exposición solar de los estudiantes, por parte de instituciones educativas públicas distritales en Colorado (Estados Unidos). La intervención implicó suministrar información sobre la política, las herramientas y la asistencia técnica, así como conformar equipos de apoyo y hacer reuniones con los administradores. Aunque no se detectaron diferencias en la cantidad de colegios que adoptaron las políticas, en comparación con los no intervenidos, los colegios intervenidos implementaron de forma significativa estrategias más fuertes para la prevención de la exposición, como provisión de sombra en el exterior, educación sobre protección solar a los estudiantes y divulgación a los padres ${ }^{28}$ (CALIDAD MUY BAJA).

El envío de notificaciones modificadas más la administración de recursos de protección de la piel a padres e hijos de cinco a nueve años de edad durante tres años, mostró un impacto positivo en el empleo de medidas de protección de barrera, el cual fue estadísticamente significativo. Sin embargo, la relación no fue clara con resultados de exposición al sol (bronceado, aparición de nevus, etc.), así como tampoco en mediadores cognitivos, como atención a los factores de riesgo y conocimiento en protección de barrera o de factores de riesgo ${ }^{29}$ (CALIDAD MODERADA).

Por otra parte, en las playas públicas de Massachusetts, se invitó a mujeres a emplear estrategias de bronceo que no emplearan el sol, con la instrucción sobre el uso de autobronceadores, resultados de estos productos, muestras gratis y enseñanza sobre los riesgos de la exposición, mientras un grupo de mujeres control completaron una 
Se recomienda, para la población general, promover medidas que reduzcan la exposición a la radiación ultravioleta y disminuyan el riesgo de desarrollar queratosis actínica, las cuales incluyen:

- Uso de medidas de barrera física (sombrero, ropa adecuada).

FUERTE,

- Evitar la exposición en horas de mayor radiación ultravioleta.

- Buscar la sombra al practicar actividades al aire libre.

- Uso de barreras químicas (protección solar).

\section{PREVENCIÓN PRIMARIA: USO DE MEDIDAS DE PROTECCIÓN FISICA}

Para la población general, se recomienda promover medidas que eviten la exposición a la radiación ultravioleta, especialmente entre las 9 a.m. y las 4 p.m.

Para la población general, se recomienda buscar la sombra al practicar actividades y en desplazamientos al aire libre.

Para la población general, se recomienda usar vestimenta apropiada: sombrero de ala ancha y ropa de manga y bota larga, que impidan el paso de la radiación ultravioleta.

PREVENCIÓN PRIMARIA: USO DE MEDIDAS TÓPICAS DE PROTECCIÓN

Se recomienda el uso de barreras químicas (protector solar) en conjunto con otras medidas de protección física, para la prevención de la queratosis actínica.

FUERTE, A FAVOR

Se recomienda que el protector solar sea de amplio espectro (rayos ultravioleta A y B), con un factor de CONSENSO protección solar de mínimo 30.

PREVENCIÓN PRIMARIA: USO DE MEDIDAS SISTÉMICAS DE PROTECCIÓN

No se recomienda, para la población general, el uso de betacaroteno para la prevención de queratosis actínica.

FUERTE

EN CONTRA

No se sugiere el uso de Polypodium leucotomos ni de extracto de corteza de pino marítimo francés, para la prevención de la queratosis actínica en la población general.

DÉBIL

EN CONTRA

FUERTE,

No se recomienda, para la población general, el uso de AINE para la prevención de la queratosis actínica.

EN CONTRA

$$
\text { PREVENCIÓN PRIMARIA: USO DE OTRAS MEDIDAS }
$$

No se sugiere prescribir dietas específicas (mayor consumo de vegetales o menor consumo de grasas) a la población general, como parte de las estrategias preventivas de la queratosis actínica.

No se recomienda el uso de cámaras de bronceo, debido al aumento del riesgo de cáncer de piel en la población general.

EN CONTRA

\section{PREVENCIÓN PRIMARIA: USO DE MEDIDAS DE SALUD PÚBLICA}

Se recomienda la realización de campañas educativas integrales (las cuales incluyen publicidad, cartillas educativas y educación dirigida a la población general) para la prevención de la queratosis actínica, las cuales proporcionen conocimientos referentes a los riesgos de la exposición a la radiación ultravioleta y promuevan la modificación de dichas conductas de riesgo.

Se recomienda que las campañas educativas integrales para la prevención de queratosis actínica (las cuales incluyen publicidad, cartillas educativas y educación dirigida a la población general), sean reforzadas periódicamente para mantener la observancia de las intervenciones preventivas.

\section{PREVENCIÓN SECUNDARIA}

Se recomienda el uso de medidas de protección física (reducir la exposición solar entre las 9 a.m. y las 4 p.m., buscar la sombra al practicar actividades y desplazamientos al aire libre, usar vestimenta apropiada: sombrero de ala ancha y ropa de manga y bota larga) y química (protector solar), para la prevención secundaria de la queratosis actínica.

Se recomienda que el protector solar sea de amplio espectro (rayos ultravioleta A y B), con un factor de protección solar de mínimo 30.

TABLA 2. Recomendaciones sobre estrategias de prevención según la fuerza de la recomendación GRADE. 
encuesta relacionada. A los dos meses de esta intervención, se reportó una disminución significativa en la exposición al sol, uso de ropa protectora y ocurrencia de quemaduras solares en las mujeres intervenidas, pero a un año no se observaron diferencias en las quemaduras solares, aunque sí en el reporte de empleo de estrategias de prevención ${ }^{30}$ (CALIDAD MUY BAJA).

\section{B. Uso de medidas de protección física}

En el ensayo clínico "Sun protection of Florida's children", se promovió el uso de sombrero dentro y fuera del colegio en estudiantes de cuarto grado, por medio de la provisión de los sombreros y la inclusión de sesiones en clase sobre su uso y normas de uso. En los colegios control, su uso se mantuvo cercano al o \%, mientras que en los colegios intervenidos alcanzó $30 \%$ y $40 \%$ de uso en el colegio en otoño y primavera, respectivamente. El autorreporte del uso de sombrero fuera del colegio y los niveles de pigmentación entre los dos grupos, no tuvo cambios significativos entre las dos poblaciones ${ }^{31}$ (CALIDAD MODERADA).

Por otra parte, en dos estudios se evaluó la relación entre el uso de cámaras bronceadoras y el riesgo de carcinoma escamocelular y basocelular. Zhang, et al. ${ }^{32}$, emplearon los datos de una cohorte de 73.494 enfermeras observadas de forma prospectiva por 20 años, entre 1989 y 2009. En estas pacientes se describió el uso de cámaras bronceadoras y, para aquellas que reportaron carcinoma basocelular o escamocelular, se corroboraron los datos con las historias clínicas. Se encontró que el riesgo de carcinoma basocelular se incrementó con el uso más frecuente al año de las cámaras, especialmente, si se había dado durante el bachillerato o la universidad (riesgo relativo, RR, de carcinoma basocelular, al menos cuatro veces al año durante el bachillerato o la universidad: 1,40; IC $\left._{95 \%} 1,30-1,52\right)$, mientras que el RR para carcinoma basocelular por exposición entre los 25 a 35 años fue de 1,19 (IC $_{95 \%}$ 1,12-1,26). En relación con el carcinoma escamocelular, el uso de cámaras, al menos, cuatro veces al año durante el bachillerato o la universidad, no mostró asociación con la incidencia de esta lesión, aunque sí se asoció con su uso, al menos, cuatro veces al año entre los 25 y 35 años (RR de carcinoma escamocelular, al menos cuatro veces al año durante el bachillerato o la universidad, 1,19) ( IC $\left._{95 \%} 0,84-1,67\right)$, mientras que el RR para carcinoma escamocelular por exposición entre los 25 y 35 años fue de 1,43 (IC $\left.{ }_{95 \%}: 1,15-1,76\right)$. En este estudio se encontró una relación dependiente de la dosis entre el número de veces que la paciente reportó exponerse al año y el riesgo de carcinoma escamocelular o basocelular. Por su parte, Karagas, et al. ${ }^{33}$, compararon 603 pacientes con carcinoma basocelular y 293 con carcinoma escamocelular, recientemente diagnosticados, versus 540 sujetos control, para determinar el antecedente de exposición a cámaras de bronceo. Se encontró una asociación positiva significativa, tanto para carcinoma basocelular $(\mathrm{OR}=1,5$; $\mathrm{IC}_{95 \%}$ 1,1-2,1) como para el escamocelular $\left(\mathrm{OR}=2,5 ; \mathrm{IC}_{95 \%}\right.$ 1,7-3,8) (CALIDAD MODERADA).

\section{Uso de medidas tópicas de protec- ción}

En un ensayo clínico publicado en 1999, se asignaron aleatoriamente sujetos entre 18 y 24 años a usar bloqueador solar con SPF (Sun Protection Factor) de 100 30, sin recomendaciones adicionales sobre otras acciones de protección solar. A pesar de que el grado de protección solar del bloqueador administrado estaba enmascarado, los sujetos con mayor SPF reportaron mayor exposición al sol y más actividades en el exterior sin protección adicional, aunque no se detectaron diferencias entre el número de quemaduras o el enrojecimiento ${ }^{34}$ (CALIDAD ALTA). En otro estudio, los sujetos fueron asignados aleatoriamente con anterioridad, para usar protector solar diariamente versus a discreción; los participantes fueron observados durante seis años para valorar la persistencia en el uso del protector. Se observó que aquellos asignados al grupo de aplicación diaria del protector fueron más proclives a mantener este hábito, en comparación con el grupo de aplicación a discreción ${ }^{35}$ (CALIDAD MODERADA).

En un ensayo clínico se evaluó el impacto del uso de bloqueador solar con SPF17 versus placebo, para la incidencia de queratosis actínica a un año de seguimiento. Se encontró que en los sujetos con placebo se incrementó en una unidad el promedio de lesiones de queratosis actínica, mientras que, en el grupo con protector solar, dicho promedio se redujo en 0,6 . El grupo protegido tuvo menos lesiones nuevas ( $\mathrm{RR}=0,62$; $\mathrm{IC}_{95 \%}$ 0,54-0,71) y más remisiones $\left(\mathrm{OR}=1,35\right.$ IC $_{95 \%}$ 1,29-1,80), comparado con el grupo con placebo. Además, se detectó una relación entre la cantidad de protector empleado y la reducción de las lesiones, o sea, entre la respuesta terapéutica y la dosis ${ }^{36}$ (CALIDAD BAJA). Asimismo, el uso diario de bloqueador solar, mostró una reducción en el número de lesiones de queratosis actínica en población australiana con edades entre 25 y 74 años a cuatro años de seguimiento (número de lesiones=1,20; $\mathrm{IC}_{95 \%}$ 1.04-1.39), comparado con la administración a discreción (razón=1,57; $\mathrm{IC}_{95 \%}$ 1.35-1.84) $^{37}$ (calidad baja). El empleo de un protector solar en pacientes sometidos a radiación solar simulada, representó una reducción significativa en el número de estratos córneos (19.8 Vs. 15.0) y granulosos (1,8 Vs. 1,1) y en la formación 
de melanina (3,2 Vs. 1,4) a seis semanas de seguimiento, comparados con aquellos sometidos a radiación sin bloqueador. Además, generó un mayor grosor de epidermis viable $(85,2 \text { Vs. 90,o })^{38}$ (CALIDAD MUY BAJA).

Por otra parte, se hizo un ensayo clínico factorial para evaluar si el uso de bloqueador solar con SPF15 más suplemento de betacaroteno (30 mg/día), con seguimiento a 4,5 años, disminuía la incidencia de cáncer basocelular o escamocelular. No se detectaron diferencias entre los grupos asignados aleatoriamente al uso diario de protector solar Vs. no uso de protector solar (carcinoma basocelular=2.588 Vs. 2.509 por 100.000; $R R=1,03$; $\mathrm{IC}_{95 \%}$ 0,73-1,46; carcinoma escamocelular=876 Vs. 996 por 100,000; RR=0,88; $\mathrm{IC}_{95 \%}$ 0,50-1,56). Sin embargo, se observaron $5 \%$ de eventos adversos relacionados con su uso diario, mientras en el grupo control no se observaron $^{39}$ (CALIDAD MODERADA).

Finalmente, se realizó el ensayo 'Veterans affairs topical tretinoin chemoprevention trial', con el fin de evaluar el efecto de la tretinoína para la prevención del cáncer de piel no melanoma. Al comparar pacientes tratados con tretinoína tópica al o,1 \% Vs. placebo, durante 1,5 a 5,5 años, no se encontraron diferencias significativas para el carcinoma basocelular $(p=0,3)$ ni el escamocelular $(p=0,4)$. Sin embargo, hubo una mayor tasa de eventos adversos en el grupo con tretinoína ${ }^{40}$ (CALIDAD MODERADA).

\section{Uso de medidas de protección sistémica}

En un estudio de casos y controles, en el cual se compararon 131 pacientes con cáncer basocelular Vs. 200 pacientes con otras lesiones cutáneas premalignas, se encontró que, ajustando por edad, sexo, tabaquismo, quemaduras solares a lo largo de la vida y lesiones actínicas, el suplemento de vitaminas, la oportunidad de haber consumido suplemento de vitaminas A, C y E fue menor en pacientes sin carcinoma basocelular $(\mathrm{OR}=0,3$; $\mathrm{IC}_{95 \%}$ 0,2-0,06). Sin embargo, se detectaron importantes fuentes de sesgo en la selección de los pacientes, por lo que se considera que los resultados no son concluyentes $^{41}$ (CALIDAD MUY BAJA). En un estudio similar en mujeres posmenopáusicas con edades entre 50 y 79 años, se asignaron aleatoriamente para recibir una dieta baja en grasa Vs. controles sin intervención en la dieta, con seguimiento cada seis meses. Con un promedio de seguimiento de 8,1 años, la dieta baja en grasa no disminuyó la incidencia de cáncer de piel no melanoma ( $\mathrm{HR}=0,98$; IC $\left._{95 \%} 0,92-1,04\right)^{42}$ (CALIDAD MODERADA). En otros estudios no se observó una relación concordante con el riesgo de carcinoma basocelular según el tipo de dieta ni con el tercil de consumo de las dietas ${ }^{43}$, excepto con aquella de carnes y grasa, la cual incrementa el riesgo hasta cuatro veces $\left(\mathrm{RR}=4,12 \mathrm{IC}_{95 \%}\right.$ 1,78-9,45), especialmente, la basada en comida diaria rica en grasa $\left(\mathrm{RR}=2,38\right.$; $\mathrm{IC}_{95 \%}$ 1,20-4,73) (CALIDAD MODERADA).

Por otra parte, en un ensayo clínico controlado con 240 sujetos con edades entre 37 y 87 años y antecedentes de queratosis actínica, se asignó aleatoriamente la administración de $200 \mathrm{mg}$ de celecoxib o placebo dos veces al día durante nueve meses. Se evaluó la incidencia de queratosis actínica a los 3, 6, 9 y 11 meses, encontrándose que a los nueve meses de seguimiento no hubo diferencias en la incidencia de queratosis actínica (diferencia de medias, $\mathrm{p}=0,43)$. A los 11 meses se detectó que, en los pacientes intervenidos con celecoxib, se presentaron menos lesiones: (promedio acumulado de tumores por paciente, 0,14 Vs. 0,35; RR=0,43, IC ${ }_{95 \%} 0,24-0,75$; $\mathrm{p}=0,003)$, diferencia que se mantuvo tanto para el carcinoma basocelular ( $\left.R R=0,40 ; I_{95 \%} 0,18-0,93 ; p=0,032\right)$ como para el escamocelular $\left(\mathrm{RR}=0,42 ; \mathrm{IC}_{95 \%} 0,19-0,93\right.$; $\mathrm{p}=0,032)$, luego de ajustar por variables de confusión. No hubo diferencias en los eventos adversos serios ni cardiovasculares entre los grupos evaluados $(R R=1,25$; $\mathrm{IC}_{95 \%} 0,48-3,26$, celecoxib Vs. $\mathrm{RR}=1,35 ; \mathrm{IC}_{95 \%} 0,44-4,14$, respectivamente $)^{45}$ (CALIDAD MODERADA).

En 1999, se llevó a cabo un ensayo clínico factorial para evaluar si el uso de bloqueador solar con SPF15 más suplemento de betacaroteno (30 $\mathrm{mg} /$ día) con seguimiento a 4,5 años, disminuye la incidencia de cáncer basocelular o escamocelular. No se detectaron diferencias significativas entre el grupo que recibió betacaroteno Vs. el grupo con placebo (carcinoma basocelular=3.954 Vs. 3.806 por 100.000; $\mathrm{RR}=1.04$ IC $_{95 \%}$ 0.73-1.27; carcinoma escamocelular = 1.508 Vs. 1.146 por $100.000 ; R R=1,35 ; I_{95 \%}$ o,84-2,19) ${ }^{39}$ (CALIDAD MODERADA). En general, el uso de betacaroteno no mostró significancia estadística para protección contra el carcinoma basocelular $(\mathrm{HR}=1,04$; $\left.\mathrm{IC}_{95 \%} 0,73-1,27\right)$ ni el escamocelular $(\mathrm{HR}=1,35 ; 0,84-2,19)$, ni tampoco en relación con eventos adversos $(R R=0,5$; IC $_{95 \%}$ 0,3 to 1,1)39 (CALIDAD MODERADA). Asimismo, otros estudios muestran que el betacaroteno no es efectivo para disminuir la incidencia de queratosis actínica a los dos años ni a los cuatro años de seguimiento $(R R=0,99$; IC $_{95 \%}$ o,80-1,24)(45) (CALIDAD BAJA).

En población australiana con edades entre 25 y 74 años, asignada aleatoriamente para usar protector solar diariamente o a discreción para reducir la aparición de lesiones de queratosis actínica, no se observó ningún impacto con el suplemento de betacaroteno (30 mg/ día) ${ }^{37}$ (CALIDAD BAJA). En un ensayo clínico factorial que tuvo como objetivo evaluar si el uso de bloqueador solar con SPF15 más suplemento de betacaroteno (30 mg/día) con seguimiento a 4,5 años, disminuye la incidencia de 


\section{FUERZA DE LA RECOMENDACIÓN GRADE \\ FUERTE, EN CONTRA}

\section{"NO SE RECOMIENDA, PARA LA POBLACIÓN GENERAL, EL USO DE BETACAROTENO PARA LA PREVENCIÓN DE QUERATOSIS ACTÍNICA".}

\author{
MEDIDAS DE PROTECCIÓN SISTÉMICA
}

cáncer basocelular o escamocelular, no se encontraron diferencias significativas en la incidencia de carcinoma basocelular ni escamocelular entre el grupo tratado con betacaroteno y el grupo placebo $\left(\mathrm{RR}=1,04 ; \mathrm{IC}_{95 \%}\right.$ 0,731,27 y RR=1,35; IC ${ }_{95 \%} 0,84-2,19$, respectivamente) ${ }^{39}$ (CALIDAD MODERADA).

Por otra parte, se llevó a cabo un estudio de casos y controles con carcinoma escamocelular, carcinoma basocelular y melanoma, entre 1991 y 2009 en Dinamarca, y se compararon con, aproximadamente, 10 poblaciones control, ajustando por importantes variables de confusión. Se evaluó el antecedente de consumo de aspirina y otros antiinflamatorios no esteroideos, (AINE) no selectivos, o inhibidores COX-2 selectivos. El antecedente de más de dos prescripciones Vs. dos o menos, se asoció con mayor riesgo de carcinoma escamocelular ( $\left.R R=0,85 ; \mathrm{IC}_{95 \%} \mathrm{O}, 76-0,94\right) \mathrm{y}$ melanoma ( $\left.\mathrm{RR}=0,87 ; \mathrm{IC}_{95 \%} \mathrm{0}, 80-0,95\right)$, especialmente, con uso de más de siete 7 años. No se asoció con carcinoma basocelular ( $\left.R R=0,97 ; I_{95 \%} 0,93-1,01\right)$, aunque a largo plazo, en sitios diferentes a cabeza y cuello, sí se encontró una asociación protectora $\left(\mathrm{RR}=0,85 ; \mathrm{IC}_{95 \%} 0,76-0,95\right)$, así como con uso intensivo $\left(\mathrm{RR}=0,79 ; \mathrm{IC}_{95 \%} 0,69-0,91\right)^{46}$.

En un segundo estudio de casos y controles, se compararon 415 pacientes con carcinoma escamocelular diagnosticados en 2004 Vs. 415 sujetos pareados por edad, sexo y raza, sin historia de cáncer. Se evaluó el antecedente de consumo de AINE en los 10 años previos, encontrándose que no hubo asociación entre su uso y el carcinoma escamocelular $\left(\mathrm{OR}=1,32 ; \mathrm{IC}_{95 \%} 0,92-1,89\right)$, aspirina $(\mathrm{OR}=1,38$; $\mathrm{IC}_{95 \%}$ 0,96-1,97), ibuprofeno (OR=0,74; IC $\left.{ }_{95 \%} 0,46-1,19\right)$, o AINE diferente a aspirina $\left(\mathrm{OR}=0,84 ; \mathrm{IC}_{95 \%} 0,56-1,26\right)$. Tampoco se detectó una asociación explorando duración, dosis o interacciones entre estas variables ${ }^{47}$.

En un tercer estudio de casos y controles, llevado a cabo en 1.621 personas de Queensland (Australia) con carcinoma escamocelular, comparadas con 187 controles pareados por edad y sexo, se reportó menor frecuencia de consumo de AINE a la semana durante más de un año $\left(\mathrm{OR}=0,07 \mathrm{IC}_{95 \%}\right.$ 0,01-0,71), o de haber usado AINE a dosis completas dos o más veces a la semana durante más de cinco años $\left(\mathrm{OR}=0,20\right.$ IC $_{95 \%}$ 0,04-0,96). Además, los pacientes con carcinoma escamocelular usuarios regulares de AINE tuvieron menor número de lesiones de queratosis actínica comparados con quienes no los utilizaban $\left(\mathrm{RR}=0,52 ; \mathrm{IC}_{95 \%} \mathrm{O}, 30-0,91\right)(48)$. En un cuarto estudio de casos y controles se encontró que el uso de AINE, especialmente la aspirina, redujo el riesgo de carcinoma escamocelular, particularmente en aquellos sensibles a la proteína p53 $\left(\mathrm{OR}=0,29 ; \mathrm{IC}_{95 \%}\right.$ 0,11-0,79). No se encontró relación entre los AINE y el carcinoma basocelular. Se encontró una discreta relación protectora entre el carcinoma escamocelular o basocelular y el acetaminofén ${ }^{49}$ (CALIDAD MODERADA).

En una población incluida en un ensayo clínico diseñado para evaluar el efecto del retinol en la incidencia de cáncer de piel no melanoma, se evaluó el efecto del consumo de AINE en este mismo resultado. Se encontró que el consumo de AINE protegió a la población con carcinoma escamocelular y basocelular $\left(\mathrm{HR}=0,49\right.$; $\mathrm{IC}_{95 \%}$ 0,28-0,87 Vs. HR=0,43; IC ${ }_{95 \%}$ 0,25-0,73, respectivamente). Se encontró que con AINE diferentes a la aspirina hubo mayor protección frente al carcinoma basocelular con un tiempo de consumo menor al de la duración del estudio. No se detectaron diferencias en la ocurrencia de eventos $\operatorname{adversos}^{50}$ (CALIDAD MODERADA).

Finalmente, en un estudio se mostró que el extracto de Polypodium leucotomos por vía oral, produjo mejoría leve en la mayor parte de pacientes con fotodermatosis idiopática (9/25), seguida por normalización de los síntomas $(7 / 25)$, sin mejoría $(5 / 25)$ y clara mejoría $(4 / 25)^{51}$. Un paciente con antecedentes de colon irritable presentó empeoramiento de los sintomas gastrointestinales. La administración oral de $7,5 \mathrm{mg} / \mathrm{kg}$ de $P$. leucotomos en nueve pacientes expuestos a radiación ultravioleta, mostró su efectividad 
como quimioprotector de la piel contra la radiación ultravioleta a 24 horas de la intervención, al disminuir significativamente el eritema, los marcadores intermedios de daño cutáneo y la infiltración mastocítica de la piel ${ }^{52}$ (CALIDAD MUY BAJA). Asimismo, la administración del extracto de pino marítimo francés a dosis diarias de $1,10 \mathrm{mg} / \mathrm{kg}$, generó una dosis mínima para eritema inducido por radiación ultravioleta de 34,62 $\mathrm{mm}^{2}$, mientras que, a 1,66 mg/kg diarios fue de $39,63 \mathrm{~mm}^{2} 53$ (CALIDAD MUY BAJA).

\section{E. Otras recomendaciones}

En personas con cáncer de piel no melanoma, el tratamiento con betacaroteno no reduce la aparición de nuevas lesiones de piel, a cinco años de tratamiento y observación $^{54}$ (CALIDAD ALTA).

\section{EVALUACIÓN DE LA QUERATOSIS ACTÍNICA}

\section{4. ¿Cuáles son las herramientas diagnósticas recomendadas para la evaluación de la queratosis actínica?}

El diagnóstico de las queratosis actínica se basa primordialmente en el examen clínico, con un valor diagnóstico positivo que varía de 74 a $94 \% 55$. Cuando existe duda clínica, el diagnóstico se confirma mediante una biopsia de piel de la lesión. Las queratosis actínicas típicas se presentan en áreas de exposición solar crónica ${ }^{56}$. Pueden ser asintomáticas o presentar prurito y ardor. Se trata de pápulas o placas eritematosas rugosas o queratósicas de 2 a $6 \mathrm{~mm}$ de diámetro que, por confluencia, pueden llegar a mayor tamaño. Además, se han descrito varias entidades clínico-patológicas: hipertróficas, atróficas, pigmentadas, proliferativas, liquenoides, acantolíticas y bowenoides. El principal diagnóstico diferencial se plantea con el carcinoma escamocelular ${ }^{57}$.

\section{5. ¿Cuáles son las intervenciones farmacológicas y no farmacológicas recomendadas para el manejo de la queratosis actínica?}

(Para una síntesis sobre las intervenciones farmacológicas y no farmacológicas recomendadas, ver la TABLA 3).

\section{A. Intervenciones tópicas}

En la revisión sistemática de Gupta, et al., solo se encontró un estudio en el cual se comparó la efectividad del adapaleno en gel al o,1 \% o 0,3\% Vs. gel-vehículo en el tratamiento de la queratosis actínica del rostro, los oídos, el cuero cabelludo, los brazos y el dorso de las manos $^{58}$. En dicho estudio (Kang, 2003), los participantes recibieron diariamente la intervención asignada durante cuatro semanas y, a continuación, dos veces al día durante nueve meses. Los autores no encontraron diferencias en los índices de mejoría global para los diferentes grupos evaluados $\left(\mathrm{RR}=2,54 ; \mathrm{IC}_{95 \%} 0,13-51,31\right)$, pero sí encontraron diferencias promedio entre el número de lesiones al inicio y al final del tratamiento (0,1 \%: Desviación media, $\mathrm{DM}=-2, \mathrm{IC}_{95 \%}-2,73$ a $-1,27 ; 0,3 \%$ : $\mathrm{DM}=-4$; $\mathrm{IC}_{95 \%}-4,73$ a $\left.-3,27\right)$, sobre todo para la concentración al o,3 \% (DM entre concentraciones $=-2$; $\left.\mathrm{IC}_{95 \%}-2,46 \mathrm{a}-1,54\right)$ (CALIDAd MODERADA).

Por otra parte, Gupta, et al., encontraron un ensayo clínico publicado por Thompson, et al., en $1993^{58}$, en el cual se comparó la efectividad en el manejo de la queratosis actínica de un bloqueador solar con SPF17 Vs. una crema base sin ingrediente activo, para que los sujetos participantes -adultos mayores de 40 años- se la aplicaran en cabeza, cuello, antebrazos y manos, a lo largo de un verano austral (septiembre de 1991 a marzo de 1992). Los investigadores encontraron un menor número de nuevas lesiones $\left(\mathrm{RR}=0,62 ; \mathrm{IC}_{95 \%} \mathrm{O}, 54-0,71\right)$ y un mayor número de remisiones $\left(\mathrm{OR}=1,53\right.$; $\left.\mathrm{IC}_{95 \%} \mathbf{1 , 2 9 - 1 , 8 0}\right)$ con el uso del bloqueador, observándose una diferencia significativa entre el número de lesiones de queratosis actínica al final del tratamiento ( $\mathrm{DM}=-1,6 ; \mathrm{IC}_{95 \%}-2,43$ a -0,77). También, se encontró que 32 sujetos en el grupo con bloqueador con SPF-17 y 28 del grupo con placebo se retiraron del estudio debido a reacciones cutáneas (CALIDAD MODERADA).

Los mismos autores de la mencionada revisión identificaron siete estudios, seis de ellos ensayos clínicos paralelos, en los cuales se comparó la efectividad del diclofenaco al $3 \%$ en ácido hialurónico en gel al 2,5 \% versus sólo ácido hialurónico (placebo), para el tratamiento de la queratosis actínica de diferente localización anatómica ${ }^{58}$, incluyendo información de un estudio (Ulrich, 2010) cuyos participantes fueron pacientes inmunosuprimidos.

En general, la duración del tratamiento osciló entre 30 y 168 días, con una evaluación de seguimiento de 4 a 16 semanas después de terminarlo. Los autores encontraron una efectividad superior del diclofenaco en los resultados de mejoría completa global, evaluada por el investigador y el participante, específicamente en los ciclos a 60 días (investigador: RR=3,06; IC ${ }_{95 \%}$ 1,21-7,77; nú- 
Se recomienda adoptar los siguientes parámetros:

- Pocas lesiones: menos de 20.

- Numerosas lesiones: 20 o más.

- Terapias dirigidas (lesion-directed therapy): son aquellas intervenciones que se realizan sobre las lesiones específicas. Estas incluyen: crioterapia, electrodesecación o legrado (curettage) y ácido tricloroacético.

CONSENSO DE EXPERTOS

- Terapia de campo (field-directed therapy): son aquellas intervenciones que se hacen sobre áreas anatómicas con lesiones clínicas y subclínicas. Estas incluyen: 5-fluorouracilo tópico, imiquimod, terapia fotodinámica, mebutato de ingenol, diclofenaco en gel y agentes químicos para exfoliación.

Se recomienda que el tratamiento más adecuado para el manejo de pacientes con diagnóstico de queratosis actínica se elija según el número de lesiones, de la siguiente manera:

- Pocas lesiones: terapia dirigida.

- Numerosas lesiones: terapia de campo.

Se recomienda que la dosis y la frecuencia de administración de los diferentes tratamientos tópicos para queratosis actínica, se ajusten según las características del paciente y según el criterio del médico tratante, teniendo en cuenta su efectividad, los efectos secundarios y el seguimiento del paciente.

Se recomiendan los siguientes tratamientos para el manejo de queratosis actínicas:

- 5 -fluorouracilo (en concentraciones desde $0,5 \%$ hasta $5 \%$, una a dos veces al día durante dos a seis semanas).

- Crioterapia

- Imiquimod al $5 \%$ (dos veces por semana durante 16 semanas) o imiquimod al 3,75\% (una vez al día durante dos semanas, seguido por dos semanas de descanso y, nuevamente, una vez al día durante dos semanas).

Se sugiere, cuando esté disponible y teniendo en cuenta los costos del medicamento, el uso del mebutato de ingenol (cara y cuero cabelludo: 0,015\%, una vez al día durante tres días; tronco y extremidades: 0,05\%, una vez al día por 2 días para el tratamiento de las queratosis actínicas.

Se sugiere el uso de terapia fotodinámica en el tratamiento de la queratosis actínica, debido a que su eficacia es similar a la crioterapia, con una tendencia a mejores resultados cosméticos, pero con costos superiores.

Se sugiere el uso de diclofenaco al 3 \% en 2,5 \% de ácido hialurónico (dos veces al día durante 8 a 12 semanas) para el tratamiento de la queratosis actínica, cuando no se disponga de los tratamientos tópicos previamente recomendados.

Se sugiere el uso de protectores solares como adyuvante del resto de tratamientos recomendados para el manejo de las queratosis actínicas, debido a su efecto en la disminución de las lesiones.

No se sugiere el láser ablativo como tratamiento inicial de la queratosis actínica, debido a los altos costos del láser en relación con otras técnicas igualmente efectivas y seguras.

No se recomienda el uso de isotretinoína tópica al o,1 \% como tratamiento de elección de las queratosis actínicas, debido a su baja efectividad, sus efectos adversos, los costos y la duración del tratamiento. 
mero medio de pacientes que requieren ser tratados para conseguir un resultado positivo $(\mathrm{NNT})=4,8$; participante: $\mathrm{RR}=2,86 ; \mathrm{IC}_{95 \%}$ 1,12-7,32; NNT=5,3) y 90 días (investigador: $\mathrm{RR}=2,5 ; \mathrm{IC}_{95 \%}$ 1,37-4,55; NNT=3,6; participante: $\mathrm{RR}=2,44$;

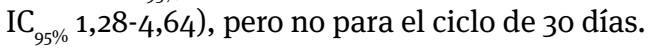

Por otra parte, se encontraron resultados a favor del diclofenaco cuando se analizó la efectividad al final del tratamiento (superior a 56 días), a los 60 a 90 días de seguimiento en las lesiones objetivo, así como en el de todas las lesiones (las objetivo y las nuevas). En el análisis del seguimiento, no se encontraron diferencias en la reducción promedio del número de lesiones a los 60 y 90 días de seguimiento, pero sí a los 30 días (DM=2,55; $\mathrm{IC}_{95 \%} 1,56$ a 3,53$)$.

Los autores también encontraron un mayor número de retiros relacionado con eventos adversos en el grupo con diclofenaco, tomando en cuenta sólo la información de los ensayos clínicos con grupos paralelos ( $R R=3,59$; $I_{95 \%}$ 1,92-6,7; NNT=9,4). Finalmente, se encontró un número alto de eventos adversos menores reportados en estudios individuales, sin diferencias significativas en la evaluación conjunta de la evidencia (CALIDAD MODERADA).

En un estudio adicional a la revisión de Gupta, et al., se evaluó la efectividad del diclofenaco al $3 \%$ dos veces al día durante 12 semanas Vs. imiquimod al $5 \%$ dos veces semana durante 16 semanas, en 61 pacientes lesiones únicas de queratosis actínica ${ }^{59}$. Los autores encontraron similares resultados en el seguimiento al final del tratamiento (12 semanas para diclofenaco y 16 para imiquimod), aunque hubo diferencias en la evaluación de los investigadores de la desaparición de las lesiones en el seguimiento a 24 semanas (DM=0,85; $\mathrm{IC}_{95 \%}$ 0,36-1,66), más no así en la evaluación de mejoría reportada por el paciente (DM=0,02; $\mathrm{IC}_{95 \%}-0,99$ a 1,05). Por otra parte, se encontró que el $75 \%$ de los que recibieron imiquimod reportaron eritema, erosión, edemas o costras, especialmente en las primeras cuatro semanas de tratamiento (CALIDAD MODERADA).

Con respecto al 5-fluorouracilo (5-FU), Gupta, et al., identificaron tres estudios en los cuales se evaluó la efectividad del 5-FU al 0,5\% versus placebo en crema, para el tratamiento de queratosis actínicas de rostro y cuero cabelludo, con administración diaria durante 1 , 204 semanas $^{58}$. Los diferentes resultados fueron evaluados hasta cuatro semanas después de finalizar el tratamiento. El análisis de subgrupos por duración del tratamiento, demostró que el 5-FU fue efectivo en la curación completa de las lesiones con administración de una semana $(\mathrm{NNT}=15,4)$, dos semanas $(\mathrm{NNT}=7,1)$ y cuatro semanas ( $\mathrm{NNT}=3,2)$, apoyando la efectividad global del 5-FU (RR=8,86; $\mathrm{IC}_{95 \%}$ 3,67- 21,4). La aplicación diaria de 5-FU durante cuatro semanas, resultó más eficaz en com- paración con los otros esquemas terapéuticos $(R R=0,39$ y 0,56, comparando una y dos semanas, respectivamente).

Sólo en un estudio se presentó información analizable sobre el número promedio de lesiones, encontrándose que el tratamiento con 5-FU durante una semana lo reducía al final del seguimiento ( $\mathrm{DM}=33,6 ; \mathrm{IC}_{95 \%} 22,8$ a $44,3)$. La evaluación de los eventos adversos muestra que los retiros asociados a este resultado pueden ser mayores en el grupo de 5-FU, comparado con el grupo con placebo $\left(\mathrm{RR}=5,4 ; \mathrm{IC}_{95 \%} 0,3-96,1\right)$ y podrían estar asociados a la duración del tratamiento ( $R R, 0,12$ a o,36, con datos estadísticamente no significativos). Asimismo, se encontró un aumento de los casos de irritación facial con el tratamiento con 5 -FU, sin diferencia entre los diferentes esquemas terapéuticos $\left(R R=1,45 ; I_{95 \%} 1,27-1,65\right)$. Otros eventos adversos menores no tuvieron diferencias significativas entre el grupo con 5-FU y el grupo con placebo (CALIDAD BAJA).

Por otro lado, los autores de la revisión encontraron un estudio intraindividual con poca información para hacer un análisis completo (Loven, 2002), en el cual se evaluó la efectividad del 5-FU al o,5 \% y al 5\%, aplicando 5 -FU 0,5\% (una vez al dia) y 5-FU 5\% (dos veces al dia), en lados opuestos de la cara, sin encontrar diferencias en los porcentajes de curación completa ${ }^{58}$. Los autores encontraron una reducción promedio de las lesiones superior en el grupo con 5-FU al 0,5 \% (DM=8,8 y 6,1, respectivamente), así como un mayor número de retiros por eventos adversos asociados al grupo con 5 -FU al $5 \%$ (8 retiros versus 4 en el grupo con 5 -FU al 0,5\%). Todos los participantes reportaron irritación facial, independientemente del grupo asignado (CALIDAD BAJA).

Respecto a la efectividad del 5-FU comparado con el imiquimod, Gupta, et al., identificaron dos estudios en los cuales se comparó la efectividad de imiquimod al $5 \%$ versus 5 -FU al $5 \%$. Los medicamentos se administraron en diferentes esquemas entre ambos estudios para queratosis actínica de diferente localización. El seguimiento de los pacientes se hizo a las ocho semanas de finalizado el tratamiento.

Los autores reportaron que los datos referentes a la curación completa no se pudieron agrupar debido a la falta de información estadística y la heterogeneidad presente en el análisis. Los RR individuales de los estudios muestran conclusiones diferenciales: en uno de ellos (Krawtchenko, 2007) no se encontraron diferencias entre ambos tratamientos, mientras que en el segundo (Tanghetti, 2007), se concluyó que el 5-FU era más efectivo. Este último estudio también reforzó su conclusión con el análisis del porcentaje promedio de reducción de lesiones, pero sin proporcionar los datos suficientes para determinar si dicha diferencia era estadística- 
mente significativa. En ninguno de los estudios se reportaron retiros por eventos adversos asociados a los diferentes tratamientos. La evaluación del investigador de los resultados cosméticos ( $\mathrm{RR}=19,3 \mathrm{IC}_{95 \%}$ 2,82-133,2; $\mathrm{NNT}=1,3)$, así como de la calidad de la piel $(\mathrm{RR}=1,45$; $\mathrm{IC}_{95 \%}$ 1,0-2,1; NNT=3,8) mostró mayores beneficios para el grupo tratado con imiquimod al $5 \%$, en comparación con el grupo con 5-FU (CALIDAD BAJA).

Asimismo, Gupta, et al., encontraron 18 estudios en los que se evaluó la efectividad del imiquimod en crema en concentraciones de 2,5 a $5 \%$, para el tratamiento de queratosis actínica en diferentes localizaciones anatómicas, comparado con placebo ${ }^{58}$. Se incluyeron ocho esquemas de tratamiento, con repetición del esquema de administración y sin él, con un número de dosis entre 12 y 56 y un seguimiento de hasta 20 semanas después de finalizarlo.

Los autores hicieron análisis por número de dosis, concentración y por frecuencia de aplicación (número de semanas). Respecto al resultado de curación completa, en general, se encontró que el tratamiento con imiquimod al $5 \%$ era más efectivo que el placebo $\left(R R=6,9\right.$; $I_{95 \%} 4,25-$ 11,26; NNT=7,7). Sin embargo, en el análisis según esquema y dosis no se obtuvieron resultados benéficos con cuatro de los ocho esquemas evaluados: 9018 dosis (tres veces por semana durante tres semanas, cuatro semanas de descanso), 24 dosis (tres veces por semana durante ocho semanas), 40 dosis (cinco veces por semana durante ocho semanas) y 56 dosis (siete veces por semana durante ocho semanas). A juicio de los autores, el número de dosis no influye sobre la efectividad del imiquimod, aunque se advierte que esta información presenta alta heterogeneidad entre los estudios incluidos.

Se encontraron resultados similares en la curación parcial ( $\geq 75 \%)$ : cuatro de los esquemas terapéuticos propuestos, no produjeron mayor efectividad que el placebo. El número de participantes con curación completa fue mayor en el grupo con imiquimod en las tres concentraciones analizadas: al 2,5\% $\left(\mathrm{RR}=4,49 ; \mathrm{IC}_{95 \%}\right.$ 2,4-8,3; NNT=4,6), al 3,75 \% (RR=6,45; $\mathrm{IC}_{95 \%} 3,87-10,73$; $\mathrm{NNT}=3,7)$ y al $5 \%\left(\mathrm{RR}=7,7 ; \mathrm{IC}_{95 \%} 4,63-12,79 ; \mathrm{NNT}=4,7\right)$, con un RR para la eficacia global de 6,73 $\left(\right.$ IC $\left._{95 \%} 5,03-9\right)$. El análisis por subgrupos para estas tres concentraciones, no reveló diferencias significativas en este resultado, pero sí en el relacionado con curación parcial, con RR de 6,7 para la concentración de $5 \%$, de 3,1 para la de 3,75 $\%$ y de 2,48 para la de $2,5 \%$.

Según la frecuencia de aplicación, los autores encontraron que el número de lesiones con curación completa y parcial aumentó, aunque no significativamente, cuando el medicamento se administró de dos a tres veces por semana, así: curación completa, con dos veces a la semana $\left(R R=5,36 ; I_{95 \%} 2,03-14,16\right)$ y con tres veces a la semana ( $\left.R R=8,38 ; I_{95 \%} 3,79-18,5\right)$; y curación parcial, con dos veces a la semana $\left(R R=4,99 ; I_{95 \%} 3,43-7,26\right)$ y con tres veces a la semana $\left(\mathrm{RR}=7,65\right.$; $\left.\mathrm{IC}_{95 \%} 2,51-23,32\right)$. El esquema de cinco veces por semana no mostró efectividad en ambos resultados, mientras que el de siete veces a la semana mostró efectividad similar a la de los esquemas de dos y tres veces por semana.

Por otra parte, la reducción promedio de lesiones solo se evaluó en un estudio (Ortonne, 2010), en el cual no se encontraron diferencias significativas entre los grupos de intervención y placebo ( $\mathrm{DM}=2,2 ; \mathrm{IC}_{95 \%}-1,05$ a 5,45). En 17 estudios se reportaron retiros por eventos adversos asociados al tratamiento. Cuando se analizó el número de dosis de imiquimod al $5 \%$, sólo se encontraron diferencias significativas para dichos retiros en la aplicación de 48 dosis $\left(\mathrm{RR}=2,69 \mathrm{IC}_{95 \%}\right.$ 1,48-4,9). Cuando se analizaron los datos por concentraciones, los grupos que recibieron imiquimod al $5 \%$ mostraron un mayor número de retiros $\left(\mathrm{RR}=2,59 ; \mathrm{IC}_{95 \%}\right.$ 1,59-4,23; NNT=27), mientras que con las otras dos concentraciones $(3,75 \%$ y $2,5 \%)$ no se demostraron diferencias en dichos eventos.

Según la frecuencia de aplicación, hubo tendencia a un mayor número de eventos para aquella de 2 y 3 veces por semana, en el grupo con imiquimod (RR para 3 veces/semana=2,47; $\mathrm{IC}_{95 \%}$ 1,42-4,3; NNT=27,2), mientras que con aquella de 507 veces por semana no se encontraron diferencias.

No se encontraron diferencias significativas en la irritación facial, cuando se analizó según la concentración, pero sí cuando se agruparon todos los datos $(\mathrm{RR}=3,93$; $\mathrm{IC}_{95 \%}$ 1,56-9,88; NNT=60). Para finalizar, en solo dos estudios se evaluaron los resultados cosméticos, encontrándose que el imiquimod al $5 \%$ produjo disminución en las asperezas, la resequedad y la descamación, en comparación con el grupo con placebo $\left(\mathrm{RR}=3,23 \mathrm{IC}_{95 \%}\right.$ 1,86-5,58; NNT=22,6) (CALIDAD BAJA-MODERADA).

Por otra parte, Gupta, et al., identificaron tres estudios sobre la efectividad del mebutato de ingenol, administrado una vez al día durante 2 a 3 días consecutivos o 1 vez a la semana durante dos semanas, en el tratamiento de queratosis actínicas de diferente localización versus placebo ${ }^{58}$. El seguimiento y la evaluación de los resultados se hicieron entre 8 y 12 semanas después de iniciado el tratamiento. Respecto a la efectividad del tratamiento en la curación completa de las lesiones (evaluada por el participante), se encontró un mayor beneficio con el mebutato de ingenol, en comparación con el placebo, tanto para las lesiones objetivo $\left(\mathrm{RR}=3,61 \mathrm{IC}_{95 \%} 1,86-\right.$ 7,02; NNT=2,9) como, en general, para todas las lesiones $\left(\mathrm{RR}=4,5 ; \mathrm{IC}_{95 \%} 2,61-7,74 ; \mathrm{NNT}=3,4\right)$.

En el análisis por subgrupos, los autores encontraron que los beneficios tienden a aumentar con la concentra- 


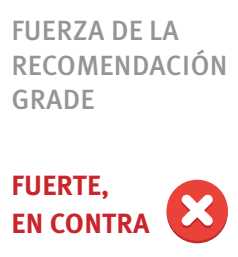

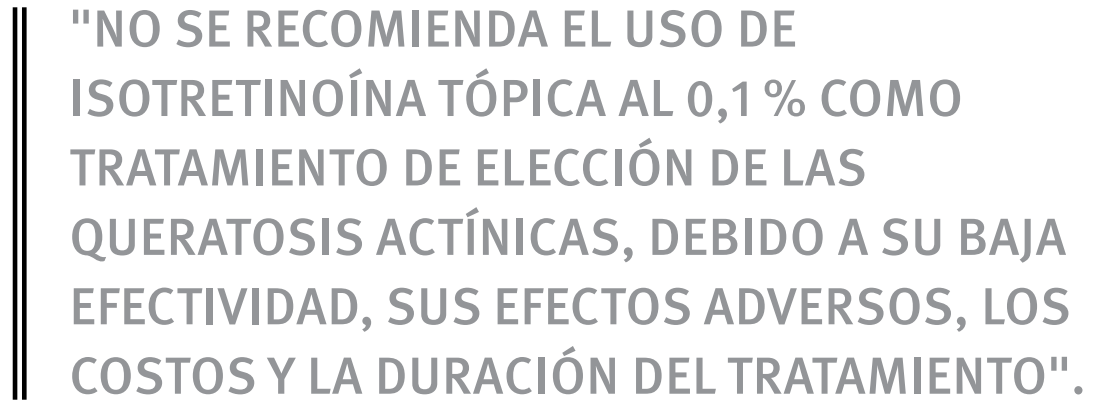

ción del ingenol (RR de 2,8 a 3,39 para las lesiones objetivo; RR de 4 a 5,14 para todas las lesiones), pero no encontraron asociación con el número de aplicaciones de ingenol al o,05\% (RR de 3,27 a 4,34 para las lesiones objetivo; RR de 4,32 a 4,08 para todas las lesiones).

Se encontraron resultados similares en la curación parcial de las lesiones $\left(\mathrm{RR}=2,88 \mathrm{IC}_{95 \%} 1,81-4,58\right.$; $\mathrm{NNT}=2,8$ ), con una similar tendencia de los beneficios con el número de aplicaciones. No se reportaron retiros asociados a eventos adversos por el tratamiento, en dos de los tres estudios incluidos. Tampoco se encontró un número significativo de casos asociado a eventos adversos menores. Sólo hubo algunos casos de pigmentación asociados al tratamiento con mebutato de ingenol, los cuales no fueron estadísticamente diferentes de los asociados al placebo $\left(\mathrm{RR}=3,36 ; \mathrm{IC}_{95 \%} \mathrm{o}, 63-17,8\right)$ (CALIDAD MODERADA-BAJA).

Finalmente, Gupta, et al., identificaron un estudio en el cual se evaluó la efectividad de la isotretinoína al o,1 \% versus placebo, administrados dos veces al día durante 24 semanas para el tratamiento de queratosis actínica de rostro, cuero cabelludo y extremidades superiores (58). Los diferentes resultados fueron valorados al final del tratamiento de 24 semanas.

En la evaluación de la efectividad por los investigadores, se encontró un bajo número de pacientes con curación completa en ambos grupos y en las tres localizaciones anatómicas mencionadas ( $R R=1,15,3,71$ y 0,93, respectivamente). Asimismo, se encontraron diferencias en el número promedio de lesiones del rostro ( $\mathrm{DM}=2,2$; IC $_{95 \%} 1,97$ a 2,43) y de las extremidades superiores $\left(\mathrm{DM}=1,9 ; \mathrm{IC}_{95 \%} 1,28-2,52\right)$.

Solo dos pacientes del grupo con isotretinoína se retiraron debido a eventos adversos del tratamiento, pero no se encontró que la diferencia, en comparación con el grupo control, fuese significativa $\left(R R=5 ; I_{95 \%} 0,25-\right.$ 101,5). Sin embargo, los autores encontraron una mayor frecuencia de irritación local del rostro $\left(\mathrm{RR}=1,57 ; \mathrm{IC}_{95 \%}\right.$ 1,23-2,01; $\mathrm{NNT}=$,3) y de irritación grave $\left(\mathrm{RR}=17,09 ; \mathrm{IC}_{95 \%}\right.$ 2,35-124,1; NNT=3,1) asociadas al tratamiento con isotretinoína (CALIDAD BAJA-MODERADA).

\section{b. Técnicas destructivas}

Gupta, et al., evaluaron diferentes estudios asociados a dos diferentes tipos de láser ablativo ${ }^{58}$. En primer lugar, se encontró un ensayo clínico (Hantash, 2006) sobre queratosis actínica del rostro, en el que se comparó la efectividad de dos pasos de remodelación con láser de dióxido de carbono (laser resurfacing) Vs. 5-FU aplicado dos veces día durante tres semanas Vs. exfoliación (peeling) con ácido tricloroacético. Los autores no encontraron diferencias significativas en la reducción promedio de las lesiones a los 12 meses de finalizado el tratamiento, en ninguno de los grupos evaluados (5-FU: $\mathrm{DM}=8,8 ; \mathrm{IC}_{95 \%}-3,16$ a 20,76; ácido tricloroacético: $\mathrm{DM}=3 \mathrm{IC}_{95 \%}-6,2$ a 12,2). Tampoco se encontraron diferencias en retiros asociados a eventos adversos, presentándose sólo dos pérdidas en el grupo con láser de dióxido de carbono (CALIDAD BAJA).

En segundo lugar, se contó con un ensayo clínico (Ostertag, 2006) en el cual se evaluó la efectividad del láser Er:YAG Vs. 5-FU al $5 \%$, aplicado este último dos veces al día durante cuatro a siete semanas, en el tratamiento de queratosis actínica de rostro y cuero cabelludo ${ }^{58}$. El análisis de la reducción promedio en el número de lesiones sugiere una efectividad similar entre los dos tratamientos (para láser Er:YAG: a tres meses, 13,8; a 6 meses, 13,9; a 12 meses, 14,2; para 5-FU: a tres 
meses, 13,2; a 6 meses, 12,5; a 12 meses, 12,4). Los autores tampoco encontraron diferencias significativas asociadas a pérdidas por eventos adversos o número de participantes que desarrollaron infecciones al final del tratamiento, pero sí en lo relacionado con el número de pacientes que desarrollaron acné o milios y aquellos con costras (mayor en el grupo con láser Er:YAG). En términos de resultados cosméticos, se encontró un mayor número de casos de hipopigmentación en el grupo con láser Er:YAG (RR=11,57; IC ${ }_{95 \%}$ 1,61-83; NNH=2,6 pacientes). Sin embargo, el uso de esta técnica mostró resultados benéficos en las puntuaciones de fotoenvejcimiento (photoageing score) a seis meses $\left(\mathrm{RR}=1,57\right.$; $\mathrm{IC}_{95 \%}$ 1,1-2,43; NNT=3,5) y 12 meses ( $R R=1,7 ; \mathrm{IC}_{95 \%}$ 1,01-2,88; $\mathrm{NNT}=3,3$ ) (CALIDAD MODERADA-BAJA).

Por otra parte, Gupta, et al., en su revisión sistemática, identificaron un ensayo clínico en el cual se comparó la efectividad de la crioterapia con nitrógeno líquido (administración única) Vs. oleogel de ácido betulínico (betulinbased oleogel) (dos veces día con duración no especificada) (Huyke, 2009) ${ }^{58}$. En la evaluación de seguimiento a tres meses, se encontraron porcentajes similares de curación completa y parcial entre los dos tratamientos evaluados (completa: $\mathrm{RR}=1,22$; $_{95 \%}$ 0,76-1,97; parcial:

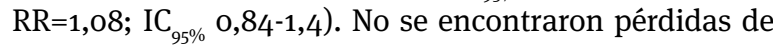
pacientes asociadas a eventos adversos (CALIDAD BAJA).

También, se contó con un ensayo en el cual se compararon la efectividad y la seguridad de la crioterapia (una o dos veces con intervalo de dos semanas) Vs. imiquimod al $5 \%$ (aplicado tres veces por semana durante cuatro meses, seguida por cuatro semanas de descanso y nueva aplicación según necesidad), para el tratamiento de lesiones actínicas ${ }^{5}$. Los autores de la revisión no encontraron diferencias significativas en la curación completa $\left(\mathrm{RR}=0,8 ; \mathrm{IC}_{95 \%}\right.$ 0,59-1,10), aunque se observó un mayor número de pacientes con este resultado en el grupo con imiquimod (22/26 pacientes). Si bien no se identificaron pérdidas por eventos adversos, se encontró un mayor número de resultados cosméticos calificados como "excelentes" en el grupo con imiquimod ( $R R=0,05$; $\mathrm{IC}_{95 \%} \mathrm{O}, 01$ $0,34)$, particularmente, en lo relacionado con la calidad cutánea (RR=0,19; IC $\left.{ }_{95 \%} 0,08-0,47 ; \mathrm{NNT}=1,5\right)$ (CALIDAD BAJA-MODERADA).

En un ensayo adicional a los incluidos en la revisión sistemática previamente citada ${ }^{60}$, se obtuvieron resultados similares en la curación completa $\left(\mathrm{RR}=1,32\right.$; $\mathrm{IC}_{95 \%}$ 0,99-1,77) en el análisis por protocolo, sin reportarse diferencias significativas en relación con el número de eventos adversos para ambos tratamientos (CALIDAD BAJA-MODERADA).

En cuatro ensayos clínicos se evaluó la efectividad de la crioterapia Vs. la terapia fotodinámica con metil- amino-levulinato (Methyl Aminolevulinate Photodynamic Therapy, MAL-PDT) al $16 \% \%^{58}$. Todos los estudios fueron abiertos y usaron terapia fotodinámica con luz roja. Respecto a los porcentajes promedio de reducción de lesiones (dos estudios), se encontró que los dos tratamientos tuvieron una eficacia similar (A 12 semanas: crioterapia, NA-74,5\%; MAL-PDT, NA-84,4\%. A 24 semanas: crioterapia, 87-83,9 \%; MAL-PDT, 75-86,7 \%). Asimismo, no se encontraron diferencias en el número de retiros asociados a eventos adversos ( $R R=1,06$; $\mathrm{IC}_{95 \%}$ o,16-7,16), en su mayoría, reacciones de fotosensibilidad y lesiones relacionadas con la exposición al frío. Los resultados cosméticos no pudieron analizarse por falta de información, pero otros datos (Szeimies, 2002) muestran una tendencia hacia mejores resultados cosméticos para el grupo con MAL-PDT (evaluado por los participantes: $\mathrm{RR}=0,93$; $\mathrm{IC}_{95 \%}$ o,86-1,01; evaluado por los investigadores: $\mathrm{RR}=0,84 ; \mathrm{IC}_{95 \%}$ o,74-0,95) (CALIDAD MUY BAJA).

Gupta, et al., identificaron dos ensayos clínicos en los cuales se evaluó la efectividad de adicionar 5-FU al 0,5\% dos veces al día durante siete días ( 1 a 3 ciclos) más crioterapia a la cuarta semana, para queratosis actínica sin mejoría Vs. crioterapia sola ${ }^{58}$. A las cuatro semanas de seguimiento, se encontraron diferencias significativas entre los tratamientos en el número de participantes con curación completa, con uno $\left(R R=1,08\right.$; $I_{95 \%}$ 1,6310,23; NNT=4,6) y dos ciclos $\left(R R=3,27 ; I_{95 \%} 1,82-5,88\right.$; $\mathrm{NNT}=2,8$ ), pero no con tres ciclos de 5 -FU. No se encontraron diferencias entre los grupos referentes a eventos adversos como irritación ocular o conjuntivitis (CALIDAD MODERADA-BAJA).

En un estudio adicional a la revisión sistemática previamente citada, se evaluó la efectividad del diclofenaco al $3 \%$ en gel más crioterapia para el tratamiento de queratosis actínica de frente, cuero cabelludo y manos $^{61}$. Los autores incluyeron 714 pacientes con edad promedio de 70 años, los cuales tenían de 5 a 15 lesiones actínicas, y fueron asignados a crioterapia con diclofenaco el gel al $3 \%$ o sin él. Después del seguimiento a 135 días, se encontraron diferencias en la desaparición completa de las lesiones objetivo (64\% para diclofenaco, $32 \%$ para crioterapia sola; $\mathrm{p}<0,0001)$ y en la desaparición completa de las lesiones objetivo y de nuevas lesiones (46\% para diclofenaco, $21 \%$ para crioterapia sola; $\mathrm{p}<0,0001)$. Asimismo, los autores reportaron que 48 pacientes asignados al tratamiento con diclofenaco más crioterapia experimentaron eventos adversos, de los cuales 31 se retiraron a causa de su gravedad, con cuatro pacientes pertenecientes al grupo de crioterapia sola (CALIDAD MUY BAJA).

Por último, Gupta, et al., identificaron tres ensayos en los cuales se evaluó la efectividad de la crioterapia com- 
binada con imiquimod al 3,75-5\% en el tratamiento de la queratosis actínica. Los autores no encontraron diferencias significativas entre los dos esquemas en cuanto la curación completa de las lesiones objetivo ( $R R=0,62$; $\mathrm{IC}_{95 \%}$ 0,36-1,04) o las lesiones subclínicas $\left(\mathrm{RR}=0,57\right.$; $\mathrm{IC}_{95 \%}$ $0,33-1,01)$. Se encontraron diferencias significativas en la reducción promedio de las lesiones con el uso de imiquimod al 3,75 \% (DM=-34.1; $\left.\mathrm{IC}_{95 \%} \mathrm{IC}_{95 \%}-41,38 \mathrm{a}-26,82\right)$.

Por otra parte, no se encontraron diferencias en el número de retiros asociados a eventos adversos $(R R=0,93$; $\mathrm{IC}_{95 \%}$ 0,28-3,07). Sin embargo, existen diferencias entre los grupos en términos de presentación de eventos adversos, como irritación cutánea, fatiga, náusea y mialgia, desfavoreciendo al grupo con imiquimod adicional; por el contrario, se presentaron resultados favorables para este último grupo en los resultados cosméticos (CALIDAD BAJA-MODERADA).

Asimismo, Gupta, et al., identificaron siete ensayos clínicos en los cuales se evaluó la efectividad de la MAL-PDT con luz roja Vs. PDT-placebo en el tratamiento de queratosis actínicas. Los resultados de efectividad favorecen la MAL-PDT, tanto en el número de pacientes con curación completa $\left(\mathrm{RR}=4,46 ; \mathrm{IC}_{95 \%} 3,17-6,28 ; \mathrm{NNT}=1,9\right)$ como en la curación parcial ( $R R=3,28$; $\mathrm{IC}_{95 \%} 1,73-6,23$; NNT=1,8). Los autores no encontraron diferencias significativas en el número de retiros asociados a eventos adversos $(\mathrm{RR}=2$; $\mathrm{IC}_{95 \%}$ 0,23-17,74), eventos adversos menores como cefalea $\left(\mathrm{RR}=3,05 ; \mathrm{IC}_{95 \%} 0,13-73,39\right)$ o resultados cosméticos como hiperpigmentación ( $\mathrm{RR}=1,42$; $\left.\mathrm{IC}_{95 \%} \mathrm{O}, 06-34,36\right)$ (CALIDAD BAJA-MUY BAJA).

Los mismos autores encontraron dos estudios en los cuales se evaluaba el tratamiento con MAL-PDT, usando dos diferentes fuentes de luz: luz roja LED Vs. luz solar, en queratosis actínicas de rostro y cuero cabelludo (58). El MAL en crema se administró por tres horas después del retiro de costras e hiperqueratosis. Los autores no encontraron diferencias en la reducción promedio de lesiones en ninguno de los seguimientos propuestos. Asimismo, no se encontraron diferencias significativas a los 12 meses de seguimiento en el número de participantes con curación completa (a 3 meses: $\mathrm{RR}=1,15 ; \mathrm{IC}_{95 \%} 0,76-1,73$; a 6 meses: $R R=1,17$; $I_{95 \%} 0,84-1,61$; a 12 meses: $R R=1,5$; $\mathrm{IC}_{95 \%}$ 0,9-2,51) o curación parcial (por seguimiento a 3 meses: $\mathrm{RR}=1,06$; $\mathrm{IC}_{95 \%}$ o,93-1,2; a 6 meses: $\mathrm{RR}=1.06$; $\mathrm{IC}_{95 \%}$ 0,93-1,2; a 12 meses: $R R=1,03$; $\left.I_{95 \%} 0,85-1,25\right)$. No se reportaron retiros de participantes, asociados a eventos adversos (CALIDAD MODERADA).

En un estudio similar, se evaluó la efectividad de diferentes tiempos de exposición a la luz solar (1,5 Vs. 2,5 horas) con el uso de terapia fotodinámica con MAL al $16 \%$ en crema, la cual fue aplicada 30 minutos antes de la exposición ${ }^{58}$. Al final de las 12 semanas de se- guimiento, no se encontró diferencia en la reducción promedio de las lesiones ( $D M=0,10 ; I_{95 \%}-3,17$ a 3,37). No se reportaron retiros de participantes, asociados a eventos adversos (CALIDAD MODERADA).

Además, Gupta, et al., identificaron un ensayo clínico adicional en el cual se evaluó si diferentes ciclos de tratamiento con MAL-PDT (dos tratamientos) eran tan efectivos como una única administración, en las queratosis actínicas ${ }^{58}$. Todas las lesiones sin mejoría a las 12 semanas, fueron tratadas nuevamente. Al final de cada ciclo, los autores encontraron un mayor número de participantes con curación completa en el grupo al que se le administró sólo una sesión de MAL-PDT $\left(\mathrm{RR}=1,17 \mathrm{IC}_{95 \%}\right.$ 1,03-1,33). Por otra parte, la diferencia en el número de retiros asociados a eventos adversos, no fue estadísticamente significativa entre los grupos evaluados $(R R=0,34$; IC $_{95 \%}$ 0,01-8,17) (CALIDAD BAJA-MUY BAJA).

\section{SEGUIMIENTO DE LA QUERATOSIS ACTÍNICA}

\section{6. ¿Cómo debe realizarse el seguimiento de pacientes con queratosis actínica?}

(Para una síntesis sobre las recomendaciones ver la TABLA 4).

Lee, et al., presentaron un sistema de cinco pasos para mejorar el manejo de los pacientes con queratosis actínica y piel con daño por luz solar ${ }^{62}$ (CALIDAD No VALORABLE). Uno de estos pasos es la evaluación clínica y periódica de la piel, acorde con los beneficios de los programas de tamización masiva de cáncer de piel. En sus recomendaciones, indican tres diferentes frecuencias de estos exámenes:

- $\quad$ Cada tres meses, en pacientes inmunosuprimidos.

- Cada seis meses, en pacientes con con daño grave por luz solar o más de 20 lesiones.

- Cada 12 meses, en pacientes con con daño moderado por luz solar o menos de 20 lesiones.

Asimismo, en la guía de práctica clínica de Berker, et al., se reporta que no existen datos sobre los beneficios del seguimiento en pacientes con queratosis actínica ${ }^{63}$ (CALIDAD No VALORABle). Se señala que los pacientes y cuidadores deben ser instruidos en el reconocimiento de los cambios en la piel que sugieren un proceso ma- 
Se recomienda el seguimiento clínico de los pacientes con queratosis actínicas cuyo tratamiento haya finalizado, de la siguiente forma:

- Cada 12 meses, en pacientes con pocas lesiones (menos de 20).

- $\quad$ Cada seis meses en pacientes con numerosas lesiones (más de 20).

TABLA 4. Seguimiento de pacientes con queratosis actínica según la fuerza de la recomendación GRADE. de una "Guía de atención integral en cáncer de piel no melanoma: queratosis actínicas” para el Ministerio de Salud y Protección Social, la cual está compuesta por una guía de práctica clínica basada en la 'evidencia', en sus versiones completa y de rápida referencia, un grupo de evaluaciones económicas y una guía informativa para pacientes y cuidadores.

FINANCIACIÓN: Programa Nacional de Ciencia, Tecnología e Innovación en Salud, Departamento Administrativo de Ciencia Tecnología e Innovación en Salud, Colciencias, Convocatoria 563/2012, Contrato 469-2012, Código de proyecto 5007-563-35261.

\section{DECLARACIÓN DE INDEPENDENCIA EDITORIAL}

La información y los datos contenidos en esta guía de práctica clínica, son el resultado de un proceso de investigación riguroso, realizado de manera independiente por el Grupo Desarrollador, el cual estuvo integrado por investigadores de la Fundación Universitaria de Ciencias de la Salud, el Instituto Nacional de Cancerología, el Centro Dermatológico Federico Lleras Acosta, E.S.E, y algunos miembros de la Asociación Colombiana de Dermatología y Cirugía Dermatológica. El ente financiador hizo seguimiento a la elaboración del presente documento, garantizando la libertad no condicionada de los contenidos de la guía. Todos los miembros del Grupo Desarrollador, participantes directos de los procesos de desarrollo, y las personas que participaron en la revisión externa, realizaron la declaración de conflictos de interés.

\section{DERECHOS DE AUTOR}

De acuerdo con el Artículo 20 de la Ley 23 de 1982, los derechos patrimoniales de esta obra pertenecen al Ministerio de Salud y Protección Social y al Departamento de Ciencia, Tecnología e Innovación (Colciencias), sin perjuicio de los derechos morales a los que haya lugar, de acuerdo con el Artículo 30 de la misma ley. Esta guía hace parte de un grupo de guías de práctica clínica que incorporan consideraciones económicas y de implementabilidad en el contexto del Sistema General de Seguridad Social en Salud colombiano, que se desarrollaron por iniciativa del Ministerio de la Salud y Protección Social en temas prioritarios y de alta prevalencia en el país. 


\section{GRUPO DESARROLLADOR DE LA GUÍA}

\section{EXPERTOS TEMÁTICOS}

\begin{abstract}
Álvaro Enrique Acosta Madiedo De Hart
Especialista en Dermatología, Especialista en Dermatología Oncológica y Cirugía Dermatológica. Coordinador, Dermatología, Instituto Nacional de Cancerología. Profesor asociado, Universidad Nacional de Colombia. Investigador principal. Líder clínico de la Guías de Práctica Clínica de Carcinoma Basocelular, Carcinoma Escamocelular y Queratosis Actínica.
\end{abstract}

\section{Xavier Rueda Cadena}

Especialista en Dermatología, Especialista en Dermatología Oncológica. Instituto Nacional de Cancerología. Coinvestigador Guía de Práctica Clínica de Carcinoma Basocelular. Coordinador clínico de las Guías de Carcinoma Escamocelular y Queratosis Actínica.

\section{John Alexander Nova Villanueva}

Especialista en Dermatología,Magíster en Epidemiología Clínica, Centro Dermatológico Federico Lleras Acosta, CDFLLA. Coinvestigador de las Guías de Práctica Clínica de Carcinoma Escamocelular y Queratosis Actínica. Coordinador clínico, Guía de Práctica Clínica de Carcinoma Basocelular.

\section{Martha Cecilia Valbuena Mesa}

Especialista en Dermatología, Especialista en Fotodermatología, Centro Dermatológico Federico Lleras Acosta, CDFLLA. Coinvestigadora de las Guías de Práctica Clínica de Carcinoma Basocelular, Carcinoma Escamocelular y Queratosis Actínica.

\section{Hugo Eduardo Herrera Nossa}

Especialista en Dermatología, Asociación Colombiana de Dermatología y Cirugía Dermatológica, Asocolderma, Universidad El Bosque. Coinvestigador de las Guías de Práctica Clínica de Carcinoma Basocelular, Carcinoma Escamocelular y Queratosis Actínica.

\section{Ana Francisca Ramírez Escobar \\ Especialista en Dermatología, Especialista en Dermato- logía Oncológica, Asociación Colombiana de Dermatología y Cirugía Dermatológica, Asocolderma. Coinvestigadora de las Guías de Práctica Clínica de Carcinoma Basocelular, Carcinoma Escamocelular y Queratosis Actínica.}

\section{Victoria Eugenia Franco Correa}

Especialista en Dermatología, Centro Dermatológico Federico Lleras Acosta, CDFLLA. Coinvestigadora de las
Guías de Práctica Clínica de Carcinoma Basocelular, Carcinoma Escamocelular y Queratosis Actínica.

\section{Guillermo Jiménez Calfat}

Especialista en Dermatología, Especialista en Dermatología Oncológica y Cirugía Dermatológica, Asociación Colombiana de Dermatología y Cirugía Dermatológica, Asocolderma. Coinvestigador de las Guías de Práctica Clínica de Carcinoma Basocelular, Carcinoma Escamocelular y Queratosis Actínica.

\section{Mariam Carolina Rolón Cadena}

Especialista en Dermatopatología. Patóloga oncóloga, Instituto Nacional de Cancerología. Coinvestigadora de las Guías de Práctica Clínica de Carcinoma Basocelular, Carcinoma Escamocelular y Queratosis Actínica.

\section{Enrique Cadena Piñeros}

Especialista en Cirugía de Cabeza y Cuello, Instituto Nacional de Cancerología, Coinvestigador de las Guías de Práctica Clínica de Carcinoma Basocelular, Carcinoma Escamocelular y Queratosis Actínica.

\section{EQUIPO METODOLÓGICO}

\section{Guillermo Sánchez Vanegas}

Especialista en Epidemiología General, Magíster en Epidemiología Clínica, Doctor en Salud Pública. Fundación Universitaria de Ciencias de la Salud, FUCS. Coordinador Metodológico de las Guías de Práctica Clínica de Carcinoma Basocelular, Carcinoma Escamocelular y Queratosis Actínica.

\section{Andrea Esperanza Rodríguez Hernández}

Especialista en Estadística Aplicada, Magíster en Epidemiología Clínica. Fundación Universitaria de Ciencias de la Salud, FUCS. Coordinadora metodológica y epidemióloga senior de la Guía de Práctica Clínica de Carcinoma Basocelular. Coinvestigadora de las Guías de Práctica Clínica de Carcinoma Escamocelular y Queratosis Actínica. Equipo de Plan de Implementación e Indicadores de las Guías de Práctica Clínica de Carcinoma Basocelular, Carcinoma Escamocelular y Queratosis Actínica.

\section{Ingrid Arévalo Rodríguez}

Magíster en Epidemiología Clínica, PhD (c) Medicina Preventiva y Salud Pública, Fundación Universitaria de Ciencias de la Salud, FUCS. Coordinadora metodológica y epidemióloga senior de las Guías de Práctica Clínica de Carcinoma Escamoceluar y Queratosis Actínica.Coinvestigadora de la Guía de Práctica Clínica de Carcinoma Basocelular. 


\section{Magda Cepeda Gil}

Magíster en Epidemiología Clínica. Fundación Universitaria de Ciencias de la Salud, FUCS. Epidemióloga de la Guía de Práctica Clínica de Carcinoma Basocelular. Epidemióloga coinvestigadora de las Guías de Práctica Clínica de Carcinoma Escamocelular y Queratosis Actínica.

\section{Omar Darío Segura}

Magíster en Epidemiología Clínica, Epidemiólogo de Campo, PhD (C) en Salud Pública. Fundación Universitaria de Ciencias de la Salud, FUCS. Epidemiólogo de las Guías de Práctica Clínica de Carcinoma Escamocelular y Queratosis Actínica. Epidemiólogo coinvestigador de la Guía de Práctica Clínica de Carcinoma Basocelular.

\section{Celmira Laza Vásquez}

Especialista en Epidemiología General, Máster en Enfermería, Fundación Universitaria de Ciencias de la Salud, FUCS. Coordinadora, Componente Cualitativo de Participación de Pacientes. Coinvestigadora de las Guías de Práctica Clínica de Carcinoma Basocelular, Carcinoma Escamocelular y Queratosis Actínica.

\section{Mónica Patricia Ballesteros Silva}

Especialista en Epidemiología General, Máster en Epidemiología Clínica, Máster en Salud Pública. PhD (C) en Medicina Preventiva y Salud Pública. Centro Cochrane Iberoamericano. Redactor general de las Guías de Práctica Clínica de Carcinoma Basocelular, Carcinoma Escamocelular y Queratosis Actínica.

\section{EQUIPO DE EVALUACIÓN ECONÓMICA}

\section{Óscar Gamboa Garay}

Especialista en Estadística, Magíster en Economía. Fundación Universitaria de Ciencias de la Salud, FUCS. Instituto Nacional de Cancerología. Coordinador, Componente de Evaluación Económica de las Guías de Práctica Clínica de Carcinoma Basocelular, Carcinoma Escamocelular y Queratosis Actínica.

\section{Carlos Adolfo Gamboa Garay}

Economista, Instituto Nacional de Cancerología.

Coinvestigador del Equipo de Evaluación Económica de las Guías de Práctica Clínica deCarcinoma Basocelular, Carcinoma Escamocelular y Queratosis Actínica.

\section{Teófilo Lozano Apache}

Ingeniero industrial, Especialista en Estadística, Instituto Nacional de Cancerología.

Coinvestigador del Equipo de Evaluación Económica de las Guías de Práctica Clínica de Carcinoma Basocelular, Carcinoma Escamocelular y Queratosis Actínica.

\section{Ana Milena Gil Quijano}

Fonoaudióloga, Magíster en Salud y Seguridad en el Trabajo. Instituto Nacional de Cancerología

Coinvestigadora del Equipo de Evaluación Económica de las Guías de Práctica Clínica de Carcinoma Basocelular, Carcinoma Escamocelular y Queratosis Actínica

\section{ESTUDIANTES DE POSTGRADO VINCULADOS AL GRUPO DESARROLLADOR}

\section{Mauricio Gamboa Arango.}

Residente de Dermatología.Fundación Universitaria Sanitas. Aprendizaje en desarrollo de Guías de Atención Integral.

\section{Jenny González Arboleda}

Residente de Dermatología, Fundación Universitaria de Ciencias de la Salud, FUCS. Aprendizaje en desarrollo de Guías de Atención Integral.

\section{Claudia Ximena Carvajal Montoya}

Residente de Dermatología, Fundación Universitaria Sanitas. Centro Dermatológico Federico Lleras Acosta, CDFLLA. Aprendizaje en desarrollo de Guías de Atención Integral.

\section{Carolina Solórzano}

Residente de Dermatología, Fundación Universitaria de Ciencias de la Salud, FUCS.

Aprendizaje en desarrollo de Guías de Atención Integral.

\section{Dirección y coordinación}

Guillermo Sánchez Vanegas, Especialista en Epidemiología General. Magíster en Epidemiología Clínica. Doctor en Salud Pública. Fundación Universitaria de Ciencias de la Salud, FUCS. Director de las Guías de Práctica Clínica de Carcinoma Basocelular, Carcinoma Escamocelular y Queratosis Actínica.

\section{Diana Carolina Buitrago García}

Enfermera, Especialización en Epidemiología Clínica, Fundación Universitaria de Ciencias de la Salud, FUCS. Coordinadora administrativa de las Guías de Práctica Clínica de Carcinoma Basocelular, Carcinoma Escamocelular y Queratosis Actínica.

\section{ASISTENTES ADMINISTRATIVOS}

\section{Yuli Paola Agudelo Camargo}

Fundación Universitaria de Ciencias de la Salud, FUCS, marzo a diciembre de 2013.

\section{Leidy Johanna León Murcia}

Fundación Universitaria de Ciencias de la Salud, FUCS. 


\section{REFERENCIAS}

1. Harvey I, Frankel S, Marks R, Shalom D, Nolan-Farrell M. Nonmelanoma skin cancer and solar keratoses. I. Methods and descriptive results of the South Wales Skin Cancer Study. Br J Cancer. 1996;74:1302-7.

2. Memon AA, Tomenson JA, Bothwell J, Friedmann PS. Prevalence of solar damage and actinic keratosis in a Merseyside population. Br J Dermatol. 2000;142:1154-9.

3. Dodson JM, DeSpain J, Hewett JE, Clark DP. Malignant potential of actinic keratoses and the controversy over treatment. A patient-oriented perspective. Arch Dermatol. 1991;127:1029-31.

4. Marks R. The epidemiology of non-melanoma skin cancer: who, why and what can we do about it. J Dermatol. 1995;22:853-7.

5. Ministerio de la Protección Social-Colciencias-CEIS. Guía metodológica para la elaboración de guías de atención integral en el Sistema General de Seguridad Social en Salud Colombiano. Bogotá: Ministerio de la Protección Social; 2010.

6. Ministerio de la Protección Social-Colciencias-CEIS. Guía metodológica para la elaboración de guías de práctica clínica con evaluación económica en el Sistema General de Seguridad Social en Salud Colombiano: Bogotá: Fundación Santa Fe de Bogotá - Centro de Estudios e Investigación en Salud; 2013.

7. Guía de práctica clínica sobre la atención al parto normal. Bilbao: Plan de Calidad para el Sistema Nacional de Salud del Ministerio de Sanidad y Política Social, Agencia de Evaluación de Tecnologías Sanitarias del País Vasco (OSTEBA), Agencia de Evaluación de Tecnologías Sanitarias de Galicia (Avalia-t). Fecha de consulta: $1^{\circ}$ de junio de 2011. Disponible en: http://portal. guiasalud.es/web/guest/catalogo-gpc?p_p_id=EXT_8 INSTANCE_YIe8\&p_p_lifecycle $=0 \& p \_p \_s t a t e=$ maximized\&p_p_ mode $=$ view\&p $p$ _col $\_$id $=$column- $3 \& p \_p$ col $\_p o s=1 \& p \_p \_$col count=2\&_EXT_8_INSTANCE_YIe8_struts_action=02Fext $\% 2 \mathrm{Fp}$ redisenyada\%2Fvista_Previa\&_EXT_8_INSTANCE_YIe8_contenidoId=57717\&_EXT_8_INSTANCE_YIe8_version=1.5.

8. Yantsos VA, Conrad N, Zabawski E, Cockerell CJ. Incipient intraepidermal cutaneous squamous cell carcinoma: A proposal for reclassifying and grading solar (actinic) keratoses. Sem Cutan Med Surg. 1999;18:3-14.

9. Padilla RS, Sebastian S, Jiang Z, Nindl I, Larson R. Gene expression patterns of normal human skin, actinic keratosis, and squamous cell carcinoma: A spectrum of disease progression. Arch Dermatol. 2010;146:288-93.

10. Cockerell CJ. Histopathology of incipient intraepidermal squamous cell carcinoma ("actinic keratosis"). J Am Acad Dermatol. 2000;42(1Pt 2):11-7.

11. Kennedy C, Bajdik CD, Willemze R, De Gruijl FR, Bouwes JN. The influence of painful sunburns and lifetime sun exposure on the risk of actinic keratoses, seborrheic warts, melanocytic nevi, atypical nevi, and skin cancer. J Invest Dermatol. 2003;120:1087-93.

12. Roewert-Huber J, Stockfleth E, Kerl H. Pathology and pathobiology of actinic (solar) keratosis - an update. Br J Dermatol. 2007;157(Suppl.2):18-20.

13. Leffell DJ. The scientific basis of skin cancer. J Am Acad Dermatol. 2000;42(1Pt 2):18-22.

14. Salasche SJ. Epidemiology of actinic keratoses and squamous cell carcinoma. J Am Acad Dermatol. 2000;42(1Pt 2):4-7.

15. Araki K, Nagano T, Ueda M, Washio F, Watanabe S, Yamaguchi $\mathrm{N}$, et al. Incidence of skin cancers and precancerous lesions in Japanese--risk factors and prevention. J Epidemiol. 1999;9(Suppl.6):S14-21.
16. Rigel DS, Rigel EG, Rigel AC. Effects of altitude and latitude on ambient UVB radiation. J Am Acad Dermatol. 1999;40:114-6.

17. Hensen P, Muller ML, Haschemi R, Stander H, Luger TA, Sunderkotter C, et al. Predisposing factors of actinic keratosis in a North-West German population. Eur J Dermatol. 2009;19:345-54.

18. Lebwohl M. Actinic keratosis: Epidemiology and progression to squamous cell carcinoma. $\mathrm{Br} \mathrm{J}$ Dermatol. 2003;149(Suppl.66):31-3.

19. Stockfleth E, Ulrich C, Meyer T, Christophers E. Epithelial malig nancies in organ transplant patients: Clinical presentation and new methods of treatment. Recent results in cancer research. Recent Results Cancer Res. 2002;160:251-8.

20. Frost CA, Green AC. Epidemiology of solar keratoses. Br J Dermatol. 1994;131:455-64.

21. Roest MA, Keane FM, Agnew K, Hawk JL, Griffiths WA. Multiple squamous skin carcinomas following excess sunbed use. J R Soc Med. 2001;94:636-7.

22. Struijk L, Hall L, van der Meijden E, Wanningen P, Bavinck JN, Neale R, et al. Markers of cutaneous human papillomavirus infection in individuals with tumor-free skin, actinic keratoses, and squamous cell carcinoma. Cancer Epidemiol Biomarkers Prev. 2006;15:529-35.

23. Ruiz de Luzuriaga AM, Ahsan H, Shea CR. Arsenical keratoses in Bangladesh--update and prevention strategies. Dermatol Clin. 2011;29:45-51.

24. Abar BW, Turrisi R, Hillhouse J, Loken E, Stapleton J, Gunn H. Preventing skin cancer in college females: Heterogeneous effects over time. Health Psychol. 2010;29:574-82.

25. Armstrong AW, Watson AJ, Makredes M, Frangos JE, Kimball $A B$, Kvedar JC. Text-message reminders to improve sunscreen use: A randomized, controlled trial using electronic monitoring. Arch Dermatol. 2009;145:1230-6.

26. Crane LA, Schneider LS, Yohn JJ, Morelli JG, Plomer KD. "Block the sun, not the fun": Evaluation of a skin cancer prevention program for child care centers. Am J Prev Med. 1999;17:31-7.

27. Sancho-Garnier H, Pereira B, Cesarini P. A cluster randomized trial to evaluate a health education programme "Living with Sun at School”. Int J Environ Res Public Health. 2012;9:2345-61.

28. Buller DB, Reynolds KD, Ashley JL, Buller MK, Kane IL, Stabell CL, et al. Motivating public school districts to adopt sun protection policies: A randomized controlled trial. Am J Prev Med. 2011;41:309-16

29. Crane LA, Asdigian NL, Baron AE, Aalborg J, Marcus AC, Mokrohisky ST, et al. Mailed intervention to promote sun protection of children: A randomized controlled trial. Am J Prev Med. 2012;43:399-410.

30. Pagoto SL, Schneider KL, Oleski J, Bodenlos JS, Ma Y. The sunless study: A beach randomized trial of a skin cancer prevention intervention promoting sunless tanning. Arch Dermatol. 2010;146:979-84

31. Hunter S, Love-Jackson K, Abdulla R, Zhu W, Lee JH, Wells KJ, et al. Sun protection at elementary schools: A cluster randomized trial. J Natl Cancer Inst. 2010;102:484-92.

32. Zhang M, Qureshi AA, Geller AC, Frazier L, Hunter DJ, Han J. Use of tanning beds and incidence of skin cancer. J Clin Oncol. 2012;30:1588-93.

33. Karagas MR, Stannard VA, Mott LA, Slattery MJ, Spencer SK, Weinstock MA. Use of tanning devices and risk of basal cell and squamous cell skin cancers. J Natl Cancer Inst. 2002;94:224-6. 
34. Autier P, Dore JF, Negrier S, Lienard D, Panizzon R, Lejeune FJ, et al. Sunscreen use and duration of sun exposure: A doubleblind, randomized trial. J Natl Cancer Inst. 1999;91:1304-9.

35. van der Pols JC, Williams GM, Neale RE, Clavarino A, Green AC. Long-term increase in sunscreen use in an Australian community after a skin cancer prevention trial. Prev Med. 2006;42:171-6.

36. Thompson SC, Jolley D, Marks R. Reduction of solar keratoses by regular sunscreen use. N Engl J Med. 1993;329:1147-51.

37. Darlington S, Williams G, Neale R, Frost C, Green A. A randomized controlled trial to assess sunscreen application and beta carotene supplementation in the prevention of solar keratoses. Arch Dermatol. 2003;139:451-5.

38. Seite S, Moyal D, Verdier MP, Hourseau C, Fourtanier A. Accumulated p53 protein and UVA protection level of sunscreens. Photodermatol Photoimmunol Photomed. 2000;16:3-9.

39. Green A, Williams G, Neale R, Hart V, Leslie D, Parsons P, et al. Daily sunscreen application and betacarotene supplementation in prevention of basal-cell and squamous-cell carcinomas of the skin: A randomized controlled trial. Lancet. 1999;354:723-9.

40. Weinstock MA, Bingham SF, Digiovanna JJ, Rizzo AE, Marcolivio $\mathrm{K}$, Hall $\mathrm{R}$, et al. Tretinoin and the prevention of keratinocyte carcinoma (basal and squamous cell carcinoma of the skin): A veterans affairs randomized chemoprevention trial. J Invest Dermatol. 2012;132:1583-90.

41. Wei Q, Matanoski GM, Farmer ER, Strickland P, Grossman L. Vitamin supplementation and reduced risk of basal cell carcinoma. J Clin Epidemiol. 1994;47:829-36.

42. Gamba CS, Stefanick ML, Shikany JM, Larson J, Linos E, Sims ST, et al. Low-fat diet and skin cancer risk: The women's health initiative randomized controlled dietary modification trial. Cancer Epidemiol Biomarkers Prev. 2013;22:1509-19.

43. Hughes MC, van der Pols JC, Marks GC, Green AC. Food intake and risk of squamous cell carcinoma of the skin in a community: the Nambour skin cancer cohort study. Int J Cancer. 2006;119:1953-60.

44. Ibiebele TI, van der Pols JC, Hughes MC, Marks GC, Williams GM, Green AC. Dietary pattern in association with squamous cell carcinoma of the skin: a prospective study. Am J Clin Nutr. 2007;85:1401-8.

45. Elmets CA, Viner JL, Pentland AP, Cantrell W, Lin HY, Bailey H, et al. Chemoprevention of nonmelanoma skin cancer with celecoxib: A randomized, double-blind, placebo-controlled trial. J Natl Cancer Inst. 2010;102:1835-44.

46. Johannesdottir SA, Chang ET, Mehnert F, Schmidt M, Olesen $\mathrm{AB}$, Sorensen HT. Nonsteroidal anti-inflammatory drugs and the risk of skin cancer: A population-based case-control study. Cancer. 2012;118:4768-76.

47. Asgari MM, Chren MM, Warton EM, Friedman GD, White E. Association between nonsteroidal anti-inflammatory drug use and cutaneous squamous cell carcinoma. Arch Dermatol. 2010;146:388-95.

48. Butler GJ, Neale R, Green AC, Pandeya N, Whiteman DC. Nonsteroidal anti-inflammatory drugs and the risk of actinic keratoses and squamous cell cancers of the skin. J Am Acad Dermatol. 2005;53:966-72.
49. Torti DC, Christensen BC, Storm CA, Fortuny J, Perry AE, Zens MS, et al. Analgesic and nonsteroidal anti-inflammatory use in relation to nonmelanoma skin cancer: A population-based case-control study. J Am Acad Dermatol. 2011;65:304-12.

50. Clouser MC, Roe DJ, Foote JA, Harris RB. Effect of non-steroidal anti-inflammatory drugs on non-melanoma skin cancer incidence in the SKICAP-AK trial. Pharmacoepidemiol Drug Saf. 2009;18:276-83.

51. Caccialanza M, Percivalle S, Piccinno R, et al. Falta citar tres autores. Photoprotective activity of oral polypodium leucotomos extract in 25 patients with idiopathic photodermatoses. Photodermatol Photoimmunol Photomed. ¿Año?;23:46-7.

52. Middelkamp-Hup MA, Pathak MA, Parrado C, Goukassian D, Rius-Diaz F, Mihm MC, et al. Oral polypodium leucotomos extract decreases ultraviolet-induced damage of human skin. J Am Acad Dermatol. 2004;51:910-8.

53. Saliou C, Rimbach G, Moini H, McLaughlin L, Hosseini S, Lee J, et al. Solar ultraviolet-induced erythema in human skin and nuclear factor-kappa-B-dependent gene expression in keratinocytes are modulated by a French maritime pine bark extract. Free Radic Biol Med. 2001;30:154-60.

54. Greenberg ER, Baron JA, Stukel TA, Stevens MM, Mandel JS, Spencer SK, et al. A clinical trial of beta carotene to prevent basal-cell and squamous-cell cancers of the skin. N Engl J Med. 1990;323:789-95.

55. Venna SS, Lee D, Stadecker MJ, Rogers GS. Clinical recognition of actinic keratoses in a high-risk population: how good are we? Arch Dermatol. 2005;141:507-9.

56. Epstein E. Quantifying actinic keratosis: Assessing the evidence. Am J Clin Dermatol. 2004;5:141-4.

57. Schmitt JV, Miot HA. Actinic keratosis: A clinical and epidemiological revision. An Bras Dermatol. 2012;87:425-34.

58. Gupta Aditya K, Paquet M, Villanueva E, Brintnell W. Interventions for actinic keratoses. Cochrane Database System Rev. 2012(12).

59. Akarsu S, Aktan S, Atahan A, Koc P, Ozkan S. Comparison of topical $3 \%$ diclofenac sodium gel and 5\% imiquimod cream for the treatment of actinic keratoses. Clin Exp Dermatol. 2011;36:479-84.

6o. Foley P, Merlin K, Cumming S, Campbell J, Crouch R, Harrison S, et al. A comparison of cryotherapy and imiquimod for treatment of actinic keratoses: lesion clearance, safety, and skin quality outcomes. J Drugs Dermatol. 2011;10:1432-8.

61. Berlin JM, Rigel DS. Diclofenac sodium 3\% gel in the treatment of actinic keratoses postcryosurgery. J Drugs Dermatol. 2008;7:669-73.

62. Lee AD, Jorizzo JL. Optimizing management of actinic keratosis and photodamaged skin: Utilizing a stepwise approach. Cutis. 2009;84:169-75.

63. de Berker D, McGregor JM, Hughes BR. Guidelines for the management of actinic keratoses. Br J Dermatol. 2007;156:222-30. 

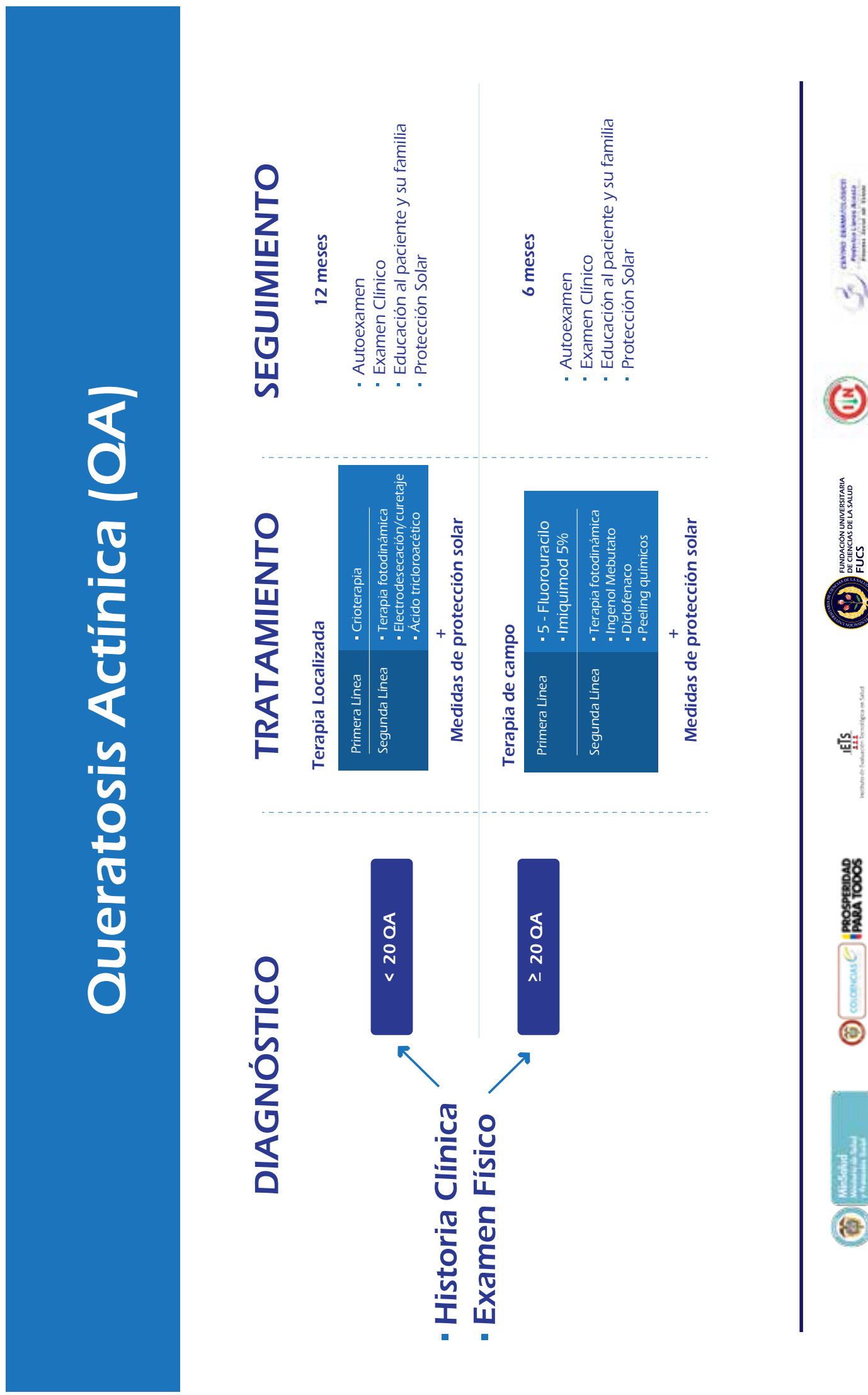

(2)
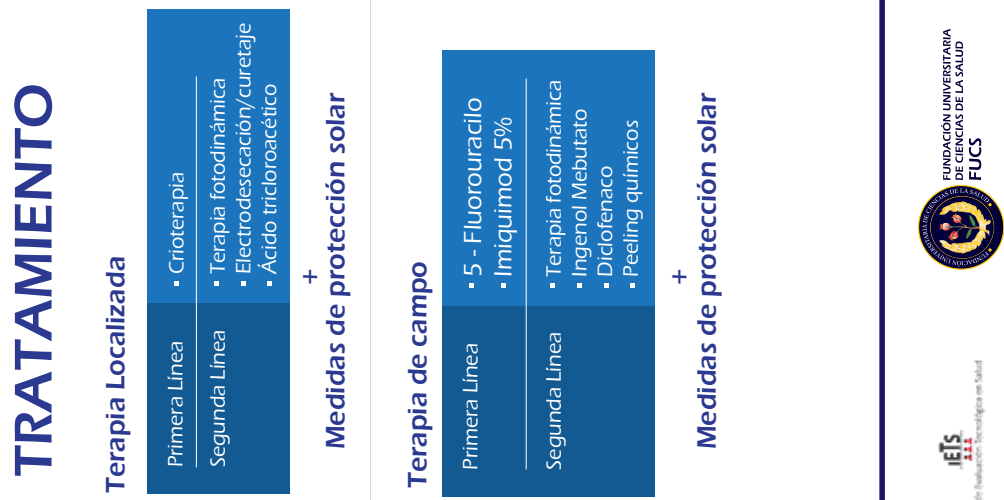

勧:

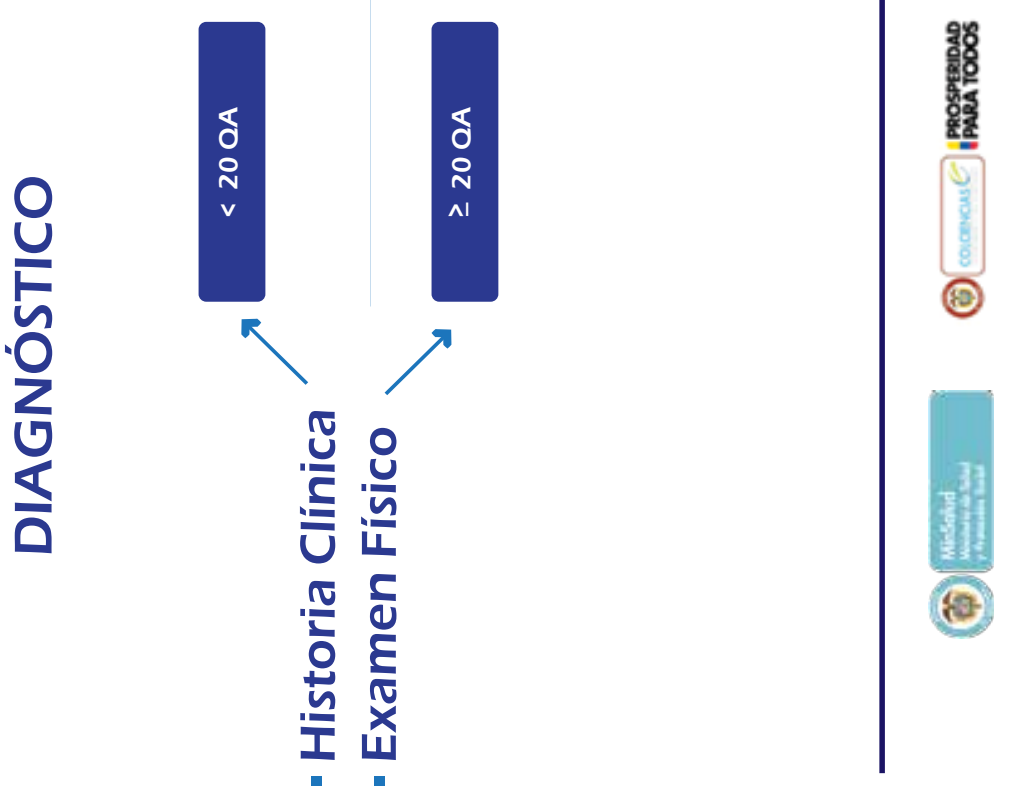

ALGORITMOS DE DIAGNÓSTICO Y TRATAMIENTO DE LA QUERATOSIS ACTÍNICA 